Cochrane Database of Systematic Reviews

\title{
Day hospital versus outpatient care for people with schizophrenia
} (Review)

Shek E, Stein AT, Shansis FM, Marshall M, Crowther R, Tyrer P

Shek E, Stein AT, Shansis FM, Marshall M, Crowther R, Tyrer P.

Day hospital versus outpatient care for people with schizophrenia.

Cochrane Database of Systematic Reviews 2009, Issue 4. Art. No.: CD003240.

DOI: 10.1002/14651858.CD003240.pub2.

www.cochranelibrary.com 
TABLE OF CONTENTS

HEADER 1

ABSTRACT

PLAIN LANGUAGE SUMMARY .....

SUMMARY OF FINDINGS

BACKGROUND

OBJECTIVES

METHODS

RESULTS

Figure 1.

DISCUSSION

AUTHORS' CONCLUSIONS

ACKNOWLEDGEMENTS

REFERENCES

CHARACTERISTICS OF STUDIES

DATA AND ANALYSES

Analysis 1.1. Comparison 1 DAY HOSPITAL versus OUT-PATIENT CARE - NEAR OR ON DISCHARGE, Outcome 1 Deaths (all causes) - day treatment centres.

Analysis 1.2. Comparison 1 DAY HOSPITAL versus OUT-PATIENT CARE - NEAR OR ON DISCHARGE, Outcome 2 Service use: Admitted to hospital during study - day treatment centres.

Analysis 1.3. Comparison 1 DAY HOSPITAL versus OUT-PATIENT CARE - NEAR OR ON DISCHARGE, Outcome 3 Global state: 1. Number lost to follow up - day treatment centres / transitional day hospital.

Analysis 1.4. Comparison 1 DAY HOSPITAL versus OUT-PATIENT CARE - NEAR OR ON DISCHARGE, Outcome 4 Global state: 2. Average score $($ GAS, high score $=$ good) - transitional day hospital.

Analysis 1.5. Comparison 1 DAY HOSPITAL versus OUT-PATIENT CARE - NEAR OR ON DISCHARGE, Outcome 5 Social functioning: 1a. Average score (CAS, high score $=$ bad) - day treatment centres.

Analysis 1.6. Comparison 1 DAY HOSPITAL versus OUT-PATIENT CARE - NEAR OR ON DISCHARGE, Outcome 6 Social functioning: 1b. Average score (SAS, high score = bad) - transitional day hospital.

Analysis 1.7. Comparison 1 DAY HOSPITAL versus OUT-PATIENT CARE - NEAR OR ON DISCHARGE, Outcome 7 Social functioning: 2. Unemployed - day treatment centres.

Analysis 1.8. Comparison 1 DAY HOSPITAL versus OUT-PATIENT CARE - NEAR OR ON DISCHARGE, Outcome 8 Mental state: 1 a. Average score (PEF, high score $=$ good) - transitional day hospital.

Analysis 1.9. Comparison 1 DAY HOSPITAL versus OUT-PATIENT CARE - NEAR OR ON DISCHARGE, Outcome 9 Mental state: 1 b. Average score (POMS, high score $=$ bad) - day treatment centres.

Analysis 1.10. Comparison 1 DAY HOSPITAL versus OUT-PATIENT CARE - NEAR OR ON DISCHARGE, Outcome 10 Mental state: $1 \mathrm{c}$.

Average score $(S C L 90$, high score $=$ bad) - day treatment centres.

ADDITIONAL TABLES

APPENDICES

WHAT'S NEW

HISTORY

CONTRIBUTIONS OF AUTHORS

DECLARATIONS OF INTEREST

SOURCES OF SUPPORT

DIFFERENCES BETWEEN PROTOCOL AND REVIEW

INDEX TERMS 
[Intervention Review]

\section{Day hospital versus outpatient care for people with schizophrenia}

Elena Shek ${ }^{1}$, Airton T Stein ${ }^{2}$, Flavio M Shansis ${ }^{3}$, Max Marshall ${ }^{4}$, Ruth Crowther ${ }^{5}$, Peter Tyrer 6

1Institute of Clinical Research India, Bangalore, India. 2Department of Public Health, Universidade Federal de Ciências da Saúde, Porto Alegre, Brazil. ${ }^{3}$ Sao Pedro Hospital, Porto Alegre, Brazil. ${ }^{4}$ University of Manchester, The Lantern Centre, Preston., UK. ${ }^{5}$ School of Population Health, University of Queensland, Queensland, Australia. ${ }^{6}$ Department of Psychological, Imperial College, London, UK

Contact address: Elena Shek, Institute of Clinical Research India, 242A, 13th Cross, CMH Road, Bangalore, Karnataka, 560038, India. elenashek@yahoo.co.uk.

Editorial group: Cochrane Schizophrenia Group

Publication status and date: Edited (no change to conclusions), published in Issue 11, 2010.

Citation: Shek E, Stein AT, Shansis FM, Marshall M, Crowther R, Tyrer P. Day hospital versus outpatient care for people with schizophrenia. Cochrane Database of Systematic Reviews 2009, Issue 4. Art. No.: CD003240. DOI: 10.1002/14651858.CD003240.pub2.

Copyright @ 2010 The Cochrane Collaboration. Published by John Wiley \& Sons, Ltd.

\section{A B S T R A C T}

\section{Background}

This review considers the use of day hospitals as an alternative to outpatient care. Two types of day hospital are covered by the review: 'day treatment programmes' and 'transitional' day hospitals. Day treatment programmes offer more intense treatment for people who have failed to respond to outpatient care. Transitional day hospitals offer time-limited care to people who have just been discharged from inpatient care.

\section{Objectives}

To assess effects of day hospital care as an alternative to continuing outpatient care for people with schizophrenia and and other similar severe mental illness.

\section{Search methods}

We searched the Cochrane Schizophrenia Group Trials Register (May 2009) and references of all identified studies for further citations. If necessary, we also contacted authors of trials for further information.

\section{Selection criteria}

Randomised controlled trials comparing day hospital care with outpatient care for those with schizophrenia and other similar severe mental illness.

\section{Data collection and analysis}

We extracted and cross-checked data independently. We analysed dichotomous data using fixed-effect relative risk (RR) and estimated the 95\% confidence interval $(\mathrm{Cl})$. If continuous data were included, we analysed this data using the random-effects weighted mean difference (MD) with a 95\% confidence interval.

\section{Main results}

We identified four relevant trials all dating from before 1986 (total $n=309$ participants); all but one of which ( $n=37$ ) evaluated day treatment centres. Across time less people allocated to day hospital care tend to be admitted to hospital (beyond one year: $\mathrm{n}=242,2 \mathrm{RCTs}, \mathrm{RR} 0.71 \mathrm{Cl}$ 0.56 to 0.89 day treatment centres) but data are heterogeneous ( $12=74 \% \mathrm{P}=0.05)$ and should not be taken into account. Data on time spent as an inpatient seem to support this finding but are poorly reported. We found no clear difference between day hospital and outpatient care for the outcome of 'lost to follow up' (at six months: n=147, 3 RCTs, RR 0.97 Cl 0.48 to 1.95; at 12 months: $n=117,2$ RCTs, RR 0.97 CI 0.48 to 1.95 day treatment centres / transitional day hospital). Scale derived findings on social functioning are equivocal (SAS: $n=37,1$ RCT, MD 
$0.36 \mathrm{Cl}-0.07$ to 0.79 transitional day hospital) but there was some suggestion from small studies that day hospital care may decrease the risk of unemployment (at 12 months: $\mathrm{n}=80,1 \mathrm{RCT}, \mathrm{RR} 0.86 \mathrm{Cl} 0.69$ to 1.06 day treatment centre). Different measures of mental state showed no convincing effect (Symptom Check List: $n=30,1 \mathrm{RCT}, \mathrm{MD}-900.31 \mathrm{Cl}-0.20$ to 0.82 day treatment centre). Poorly reported economic data from decades ago suggested that day hospitals were more costly to establish and run than outpatient care but took no account of other costs such as inpatient stay.

\section{Authors' conclusions}

Evidence is limited and dated. Day hospital care may help avoid inpatient care but data are lacking on missing on a raft of outcomes that are now considered important, such as quality of life, satisfaction, healthy days, and cost.

\section{PLAIN LANGUAGE SUMMARY}

\section{Day hospital versus outpatient care for people with schizophrenia}

Psychiatric day hospitals offer care that is less restrictive than inpatient care but more intense than outpatient care. Day hospitals can be used to provide more intense/specialised outpatient care to people resistant to treatment (day treatment programmes) or to those needing long-term care (day care centres). They can also bridge the gap between inpatient and outpatient care (transitional day hospitals). This review compared day hospital care (in day treatment centres and transitional day hospitals) to outpatient care. Overall there was insufficient evidence to determine whether any of the three types of day hospital care had substantial advantages over outpatient care. 


\section{SUMMARY OF FINDINGS}

Summary of findings for the main comparison. DAY HOSPITAL versus OUT-PATIENT CARE for people with schizophrenia near or on discharge

DAY HOSPITAL versus OUT-PATIENT CARE for people with schizophrenia near or on discharge

Patient or population: patients with people with schizophrenia near or on discharge

Settings: high income countries

Intervention: DAY HOSPITAL versus OUT-PATIENT CARE

\begin{tabular}{|c|c|c|c|c|c|c|}
\hline \multirow[t]{2}{*}{ Outcomes } & \multicolumn{2}{|c|}{ Illustrative comparative risks* $(95 \% \mathrm{CI})$} & \multirow{2}{*}{$\begin{array}{l}\text { Relative ef- } \\
\text { fect } \\
(95 \% \mathrm{CI})\end{array}$} & \multirow{2}{*}{$\begin{array}{l}\text { No of Partici- } \\
\text { pants } \\
\text { (studies) }\end{array}$} & \multirow{2}{*}{$\begin{array}{l}\text { Quality of the } \\
\text { evidence } \\
\text { (GRADE) }\end{array}$} & \multirow[t]{2}{*}{ Comments } \\
\hline & Assumed risk & Corresponding risk & & & & \\
\hline \multirow{3}{*}{$\begin{array}{l}\text { Service use: 1a. Admitted to } \\
\text { hospital during study - by } 6 \\
\text { months }\end{array}$} & \multicolumn{2}{|c|}{ Study population } & \multirow{3}{*}{$\begin{array}{l}\text { RR 0.58 } \\
\text { (0.26 to } 1.33 \text { ) }\end{array}$} & \multirow{3}{*}{$\begin{array}{l}110 \\
\text { (2 studies) }\end{array}$} & \multirow{3}{*}{$\begin{array}{l}\oplus \oplus \oplus \ominus \\
\text { moderate }^{1}\end{array}$} & \multirow{3}{*}{$\begin{array}{l}\text { See 'Effects of in- } \\
\text { terventions'Â } 1.3\end{array}$} \\
\hline & \multicolumn{2}{|c|}{ Medium risk population } & & & & \\
\hline & 150 per 1000 & $\begin{array}{l}87 \text { per } 1000 \\
(39 \text { to } 200)\end{array}$ & & & & \\
\hline \multirow{3}{*}{$\begin{array}{l}\text { Service use: 1b. Admitted to } \\
\text { hospital during study - by/at } 12 \\
\text { months }\end{array}$} & \multicolumn{2}{|c|}{ Study population } & \multirow{3}{*}{$\begin{array}{l}\text { RR } 0.73 \\
(0.54 \text { to } 1)\end{array}$} & \multirow{3}{*}{$\begin{array}{l}242 \\
\text { (2 studies) }\end{array}$} & \multirow{3}{*}{$\begin{array}{l}\oplus \oplus \ominus \ominus \\
\text { low }^{2,3}\end{array}$} & \multirow{3}{*}{$\begin{array}{l}\text { See 'Effects of in- } \\
\text { terventions' } 1.3\end{array}$} \\
\hline & \multicolumn{2}{|c|}{ Medium risk population } & & & & \\
\hline & 469 per 1000 & $\begin{array}{l}\mathbf{3 4 2} \text { per } \mathbf{1 0 0 0} \\
\text { (253 to } 469)\end{array}$ & & & & \\
\hline \multirow{3}{*}{$\begin{array}{l}\text { Service use: 1c. Admitted to } \\
\text { hospital during study - beyond } \\
12 \text { months }\end{array}$} & \multicolumn{2}{|c|}{ Study population } & \multirow{3}{*}{$\begin{array}{l}\text { RR } \mathbf{0 . 7 1} \\
\text { (0.56 to } 0.89)\end{array}$} & \multirow{3}{*}{$\begin{array}{l}242 \\
\text { ( } 2 \text { studies) }\end{array}$} & \multirow{3}{*}{$\begin{array}{l}\oplus \oplus \oplus \ominus \\
\text { moderate } 4\end{array}$} & \multirow{3}{*}{$\begin{array}{l}\text { See 'Effects of in- } \\
\text { terventions' } 1.3\end{array}$} \\
\hline & 639 per 1000 & $\begin{array}{l}\mathbf{4 5 4} \text { per } 1000 \\
\text { (358 to } 569)\end{array}$ & & & & \\
\hline & \multicolumn{2}{|c|}{ Medium risk population } & & & & \\
\hline
\end{tabular}




\begin{tabular}{|c|c|c|c|c|c|c|}
\hline \multirow{5}{*}{ 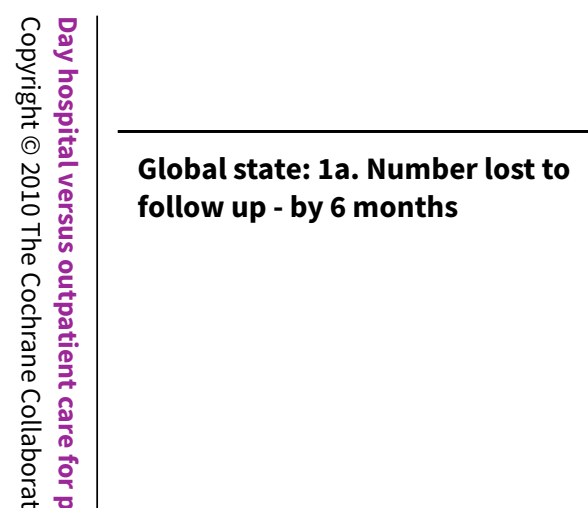 } & 623 per 1000 & \multirow[t]{2}{*}{$\begin{array}{l}\mathbf{4 4 2} \text { per } 1000 \\
(349 \text { to } 554)\end{array}$} & & & & \\
\hline & Study population & & \multirow{4}{*}{$\begin{array}{l}\text { RR } 0.97 \\
(0.48 \text { to } 1.95)\end{array}$} & \multirow{4}{*}{$\begin{array}{l}147 \\
\text { (3 studies) }\end{array}$} & \multirow{4}{*}{$\begin{array}{l}\oplus \oplus \oplus \odot \\
\text { moderate }\end{array}$} & \multirow{4}{*}{$\begin{array}{l}\text { See 'Effects of in- } \\
\text { terventions' } 1.2\end{array}$} \\
\hline & 164 per 1000 & $\begin{array}{l}159 \text { per } 1000 \\
(79 \text { to } 320)\end{array}$ & & & & \\
\hline & \multicolumn{2}{|c|}{ Medium risk population } & & & & \\
\hline & 100 per 1000 & $\begin{array}{l}97 \text { per } 1000 \\
\text { (48 to } 195)\end{array}$ & & & & \\
\hline \multirow{4}{*}{$\begin{array}{l}\text { Global state: } 1 \text { b. Number lost to } \\
\text { follow up - by/at } 12 \text { months }\end{array}$} & Study popula & & \multirow{4}{*}{$\begin{array}{l}\text { RR } 0.97 \\
(0.48 \text { to } 1.95)\end{array}$} & \multirow{4}{*}{$\begin{array}{l}117 \\
\text { (2 studies) }\end{array}$} & \multirow{4}{*}{$\begin{array}{l}\oplus \oplus \ominus \ominus \\
\operatorname{low}^{2,6}\end{array}$} & \multirow{4}{*}{$\begin{array}{l}\text { See 'Effects of in- } \\
\text { terventions' } 1.2\end{array}$} \\
\hline & 207 per 1000 & $\begin{array}{l}201 \text { per } 1000 \\
\text { (99 to } 404)\end{array}$ & & & & \\
\hline & \multicolumn{2}{|c|}{ Medium risk population } & & & & \\
\hline & 272 per 1000 & $\begin{array}{l}\mathbf{2 6 4} \text { per } \mathbf{1 0 0 0} \\
(131 \text { to } 530)\end{array}$ & & & & \\
\hline \multirow{4}{*}{$\begin{array}{l}\text { Social functioning: } 2 a \text {. Unem- } \\
\text { ployed - by } 6 \text { months }\end{array}$} & \multicolumn{2}{|c|}{ Study population } & \multirow{4}{*}{$\begin{array}{l}\mathbf{R R} \mathbf{0 . 0 4} \\
(0 \text { to } 0.62)\end{array}$} & \multirow{4}{*}{$\begin{array}{l}30 \\
\text { (1 study) }\end{array}$} & \multirow{4}{*}{$\begin{array}{l}\oplus \oplus \ominus \ominus \\
\text { low }^{6,7}\end{array}$} & \multirow{4}{*}{$\begin{array}{l}\text { See 'Effects of in- } \\
\text { terventions' } 3.2\end{array}$} \\
\hline & 800 per 1000 & $\begin{array}{l}32 \text { per } 1000 \\
\text { (0 to } 496)\end{array}$ & & & & \\
\hline & \multicolumn{2}{|c|}{ Medium risk population } & & & & \\
\hline & 800 per 1000 & $\begin{array}{l}32 \text { per } 1000 \\
\text { (0 to } 496)\end{array}$ & & & & \\
\hline \multirow{4}{*}{$\begin{array}{l}\text { Social functioning: } 2 \mathrm{~b} \text {. Unem- } \\
\text { ployed - beyond } 12 \text { months }\end{array}$} & \multicolumn{2}{|c|}{ Study population } & \multirow{4}{*}{$\begin{array}{l}\text { RR } 0.86 \\
(0.69 \text { to } 1.06)\end{array}$} & \multirow{4}{*}{$\begin{array}{l}80 \\
(1 \text { study) }\end{array}$} & \multirow{4}{*}{$\begin{array}{l}\oplus \oplus \oplus \ominus \\
\text { moderate }^{8}\end{array}$} & \multirow{4}{*}{$\begin{array}{l}\text { See 'Effects of in- } \\
\text { terventions' } 3.2\end{array}$} \\
\hline & 875 per 1000 & $\begin{array}{l}\mathbf{7 5 2} \text { per } 1000 \\
\text { (604 to } 927)\end{array}$ & & & & \\
\hline & \multicolumn{2}{|c|}{ Medium risk population } & & & & \\
\hline & 875 per 1000 & $\begin{array}{l}\mathbf{7 5 2} \text { per } \mathbf{1 0 0 0} \\
\text { (604 to } 927)\end{array}$ & & & & \\
\hline
\end{tabular}




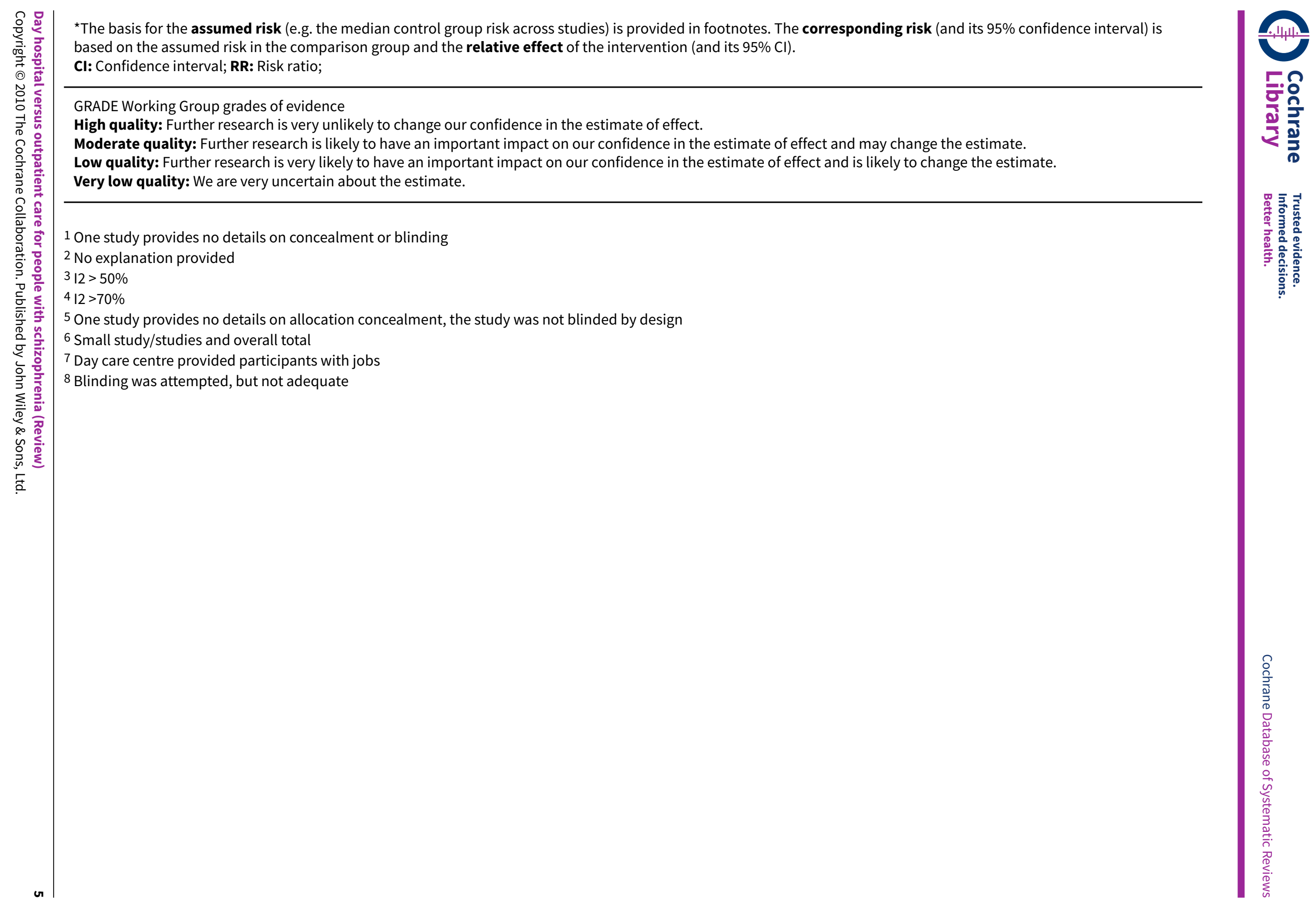




\section{B A C K G R O U N D}

Since the 1960s there has been an almost worldwide trend towards the closure of institutions for people with mental illness. Coupled with these closures, many government policies have focused on reducing the number of hospital beds for people with severe mental illness in favour of providing care in a variety of non-hospital settings - outpatient clinics, day centres or community mental health centres. These changes were consistent with the increasing shift from hospital-based care in favour of a more communityfocused approach (Malone 2007).

\section{Description of the condition}

Worldwide, more than $25 \%$ of people develop one or more mental or behavioural disorders, during their entire lifetime (WHO 2001). Schizophrenia is one such illness, heavily contributing to the numbers of people considered severely mentally ill. The lifetime prevalence of schizophrenia alone is one per cent in the adult population (Warner 1995). Currently schizophrenia is 26th on the list of diseases ranked according to contribution to overall burden in terms of disability-adjusted life years (DALYs). Its ranking is projected to rise to 20th by the year 2020, with more than 17 million DALYs lost (accounting for 1.25\% of overall burden) (Murray 1996).

\section{Description of the intervention}

The psychiatric day hospital (or 'partial hospitalisation program' as it is called in the USA) has been defined as "an ambulatory treatment program that includes the major diagnostic, medical, psychiatric, psychosocial, and pre-vocational treatment modalities designed for people with serious mental disorders who require co-ordinated, intensive, comprehensive, and multi-disciplinary treatment not provided in an outpatient clinic setting" (Casarino 1982). The day hospital was originally developed as an alternative to inpatient care (Cameron 1947) but it can also be used as an alternative to outpatient care.

The term 'day treatment programme' is usually applied to day hospitals (Rosie 1987). The day hospital can bridge the gap between hospital and outpatient care for people who have just been discharged from inpatient care. The term 'transitional day care' is usually applied to day hospitals used in this way (Glick 1986). 'Day care centres' are usually similar in their remit to that of day hospitals but tend not to be run by hospitals or hospital staff. In doing so they may have a more social and less medical focus (Rosie 1987).

\section{How the intervention might work}

Day hospitals may afford a greater intensity of treatment and closer engagement with services than that available through outpatient care alone. It has been proposed that people with severe mental illness might experience greater symptomatic improvement with the more intensive input offered by the day hospital (Bateman 2000, Moscowitz 1980, Schene 1988) when compared with people given outpatient care. Those with severe long-term disorders might experience closer engagement (Lamb 1967), and hence improved clinical outcome (Lamb 1967) and a reduced readmission rate (Guidry 1979, Moscowitz 1980), when given access to the structured support and a range of treatments offered by long-term attendance at a day hospital. Alongside the above, other benefits may include reduced cost of care and reduced duration of readmission.

\section{Why it is important to do this review}

Psychiatric day hospitals offer considerable care to large numbers of people with severe mental illnesses. Proponents have claimed that it can provide more cost-effective care by promoting quicker recovery (Cameron 1947), improving social functioning (Greene 1981, Schene 1986), reducing family burden (Pang 1985), shortening the duration of hospital care (Parker 1990) and reducing relapse rates (Moscowitz 1980). Critics of day treatment programmes, however, have argued that people who use them find day treatment programmes "neither congenial nor especially helpful" (Anonymous 1987), that day hospitals 'institutionalise' people and fail to provide focused, effective treatment (Hoge 1992, Pryce 1982, Tantam 1989) and highlight high rates of loss to follow up in day hospital studies (Wilkinson 1984). This review substantially updates the previous version of this Cochrane review (Marshall 2001).

\section{O B JECT IVES}

To assess the effects of day hospital care as an alternative to continuing outpatient care for people with schizophrenia.

\section{METHODS}

\section{Criteria for considering studies for this review}

\section{Types of studies}

All relevant randomised controlled trials (RCTs). We did not include quasi-randomised studies, such as those allocating by using alternate days of the week. If trials were described in some way as to suggest or imply that the study was randomised and the demographic details of each group's participants were similar, we included these trials and undertook a sensitivity analysis on primary outcomes to see if substantive differences resulted from inclusion of these data.

\section{Types of participants}

People aged between 18-65 years, suffering from illness such as schizophrenia, schizophrenia-like disorders and bipolar disorder. Only those not acutely ill were included. Substance abuse was not considered to be a severe mental disorder in its own right. However studies were eligible if they dealt with people with both diagnoses - that is those with severe mental illness plus substance abuse. For the purposes of this review dementia and learning disabilities were not considered to be severe mental disorders.

\section{Types of interventions}

1. Day hospital: an ambulatory treatment program organised by health care professionals that may include diagnostic, medical, psychiatric, psychosocial and pre-vocational treatment modalities designed for people with serious mental disorders who require coordinated, intensive, comprehensive and multi-disciplinary treatment not provided in an outpatient clinic setting (similar definition to Casarino 1982). For example, day hospital care may include individual psychoanalytic psychotherapy, group therapy, expressive therapy, community meetings, meeting with case administrator, medication review, education and support. Designations of 'day centres', 'day treatment centres' and 'transitional day hospitals' tend to be used interchangeably and there is confusion in this area. We suggest that day centres are mostly organised and run outside of health services and do 
not have emphasis on medication and diagnoses. Day treatment centres are more under the auspices of health services and tend to focus not only on social problems, employment etc. but also medical care of the people attending - including use of medication. Finally 'transitional day hospitals' tend to be run by the health services but are used to help the transition from ward to community or even vice versa. The may be used to avoid admission as a compromise rather than full admission as an inpatient.

2. Outpatient care: office-based practice which aims to provide support and maintenance therapy for people with mental disorders. This is usually conducted by one health care professional, often a medical practitioner psychiatrist or specialised nurse. Care involves symptom assessment, identification of adverse effects, adjustment of chemotherapy and perhaps social assistance. Each appointment is often less than thirty minutes and may be once every week, but is more commonly once every few weeks or months.

\section{Types of outcome measures}

All outcomes were grouped by time into short term (up to 6 months), medium term (7 months to 12 months) and long term (over 12 months). Where available, 24 months was the preferred follow-up point for calculating mean days per months in hospital. When more than one follow up point within the same period was available we reported the latest one.

\section{Primary outcomes}

\section{Service use}

1.1 Hospitalisation: mean number of days per month in hospital 1.2 Not remaining in contact with psychiatric services

\section{Secondary outcomes}

1. Death - suicide and all causes

2. Service use

2.1 Hospitalisation: Admitted to hospital across time

2.2 Hospitalisation: Number of admissions across time

2.3 Use of services outside of mental health provision (i.e. emergency services)

\section{Global state}

3.1 Leaving the study early (lost to follow up)

3.2 Relapse (as defined in trial)

3.3 Not improved to a clinically meaningful extent (as defined in trial)

3.4 Not improved

3.5 Improvement - average endpoint score

3.6 Improvement - average change score

3.7 Compliance with medication

3.7.1 Compliance - average endpoint score

3.7.2 Compliance - average change score

\section{Social functioning}

4.1 Imprisonment (i.e. police contacts \& arrests)

4.2 Employment status (number unemployed at end of study)

4.3 Accommodation status (number homeless or not living independently during or at the end of the study, mean days homeless and mean days in stable accommodation per month in study)

4.4 Alcohol use

4.5 Illicit drug use
4.5.1 Illicit drug use - average endpoint score

4.5.2 Illicit drug use - average change score

5. Mental state

5.1 General symptoms

5.1.1 Not improved to a clinically meaningful extent (as defined in trial)

5.1.2 Not improved

5.1.3 Average endpoint score

5.1.4 Average change score

5.2 Specific symptoms

5.2.1 Positive symptoms (delusions, hallucinations, disordered thinking)

5.2.1.1 Not improved to a clinically meaningful extent (as defined in trial)

5.2.1.2 Not improved

5.2.1.3 Average endpoint score

5.2.1.4 Average change score

5.2.2 Negative symptoms (avolition, poor self-care, blunted affect)

5.2.2.1 Not improved to a clinically meaningful extent (as defined in trial)

5.2.2.2 Not improved

5.2.2.3 Average endpoint score

5.2.2.4 Average change score

5.2.3 Mood depression

5.2.3.1 Not improved to a clinically meaningful extent (as defined in trial)

5.2.3.2 Not improved

5.2.3.3 Average endpoint score

5.2.3.4 Average change score

6. Behaviour

6.1 General behaviour

6.1.1 Not improved to a clinically meaningful extent (as defined in trial)

6.1.2 Not improved

6.1.3 Average endpoint score

6.1.4 Average change score

6.2 Specific behaviours (i.e. self-harm; injury to others or property)

7. Quality of life

7.1 Not improved to a clinically meaningful extent (as defined in trial)

7.2 Not improved

7.3 Average endpoint score

7.4 Average change score

7.5 Patient satisfaction

7.5.1 Not improved to a clinically meaningful extent (as defined in trial)

7.5.2 Not improved

7.5.3 Average endpoint score

7.5.4 Average change score

7.6 Carer satisfaction

7.6.1 Not improved to a clinically meaningful extent (as defined in trial)

7.6.2 Not improved

7.6.3 Average endpoint score

7.6.4 Average change score

8. Economic

8.1 Costs of psychiatric hospital care 
8.2 Costs of health care (including all medical and psychiatric care and the costs of case management but excluding accommodation other than hospital care)

8.3 Costs of all care (including costs of accommodation and subtracting benefits (such as earnings) where these are known)

\section{Search methods for identification of studies}

1. We searched the Cochrane Schizophrenia Group Trials Register (May 2009). This register is compiled by systematic searches of major databases like CINAHL, EMBASE, MEDLINE, PsycINFO as well as hand searches and conference proceedings (see Group Module).

2. For search methods of earlier versions of this review (Marshall 2001) please see appendix (Appendix 1).

\section{Electronic searches}

The Cochrane Schizophrenia Group Trials Register (May 2009) was searched using the phrase:

("transitional* OR * posthospital* OR *partial hospitali?ation* $O R$ *daily living programme* $O R{ }^{*}$ Ambulatory treatment* $O R$ * patient care team* $\mathrm{OR}{ }^{*}$ community mental health* $\mathrm{OR}$ * patient participation* OR *drop-in hospital* OR *drop-in care* OR *dropin treatment* $O R{ }^{*}$ drop-in cent ${ }^{*} O R^{*}$ drop-in unit ${ }^{*} O R{ }^{*}$ drop in hospital ${ }^{*}$ OR *drop in care* OR *drop in treatment* OR *drop in cent ${ }^{\star} \mathrm{OR}{ }^{\star}$ drop in unit* $\mathrm{OR}{ }^{\star}$ day hospital ${ }^{\star} \mathrm{OR}{ }^{\star}$ day care* $\mathrm{OR}$ *day treatment ${ }^{\star} \mathrm{OR}{ }^{\star}$ day cent ${ }^{\star} \mathrm{OR}$ * day unit* $\mathrm{OR}{ }^{*}$ care program approach* OR *care programme* in title, abstract, index terms of REFERENCE and in interventions of STUDY) OR ( ${ }^{*} \mathrm{Pact}^{\star} \mathrm{OR}^{*}{ }^{*} \mathrm{Cl}{ }^{*}$ In title) OR (Pact* OR tcl ${ }^{*}$ in abstract and index terms of REFERENCE and in interventions of STUDY)

\section{Searching other resources}

\section{References}

Should an included or excluded study suggest that another study was of relevance, the reference was identified and the full text acquired.

\section{Personal contact}

Where required for additional data we contacted authors of trials for this information. We did not systematically contact all authors for additional papers. We contacted relevant pharmaceutical companies and drug approval agencies for additional information.

\section{Data collection and analysis}

\section{Selection of studies}

The principal review author (ES) inspected all abstracts of studies identified as above and identified potentially relevant reports. In addition, to ensure reliability, authors AS and FS inspected a random sample of these abstracts, comprising $10 \%$ of the total. Where disagreement occurred this was resolved by discussion, or where there was still doubt, the full article was acquired for further inspection. The full articles of relevant reports were acquired for reassessment and carefully inspected for a final decision on inclusion (see Criteria for considering studies for this review). Once the full articles were obtained, authors ES, AS and FS inspected all full reports and independently decided whether they met inclusion criteria. Authors ES, AS and FS were not blinded to the names of the authors, institutions or journal of publication. Where difficulties or disputes arose, we asked Clive Adams (Co-ordinating editor of the
Cochrane Schizophrenia Group) for help and if it was impossible to decide, these studies were added to those awaiting assessment and the authors of the papers contacted for clarification.

\section{Data extraction and management}

\section{Extraction}

\subsection{Data regarding criteria and outcomes}

Authors ES, AS and FS independently extracted data from included studies. Again, any disagreement was discussed, decisions documented and, if necessary, authors of studies were contacted for clarification. With remaining problems Clive Adams again helped clarify issues and those final decisions were documented. Data presented only in graphs and figures were extracted whenever possible, but were included only if all review authors independently came to the same results. Attempts were made to contact authors through an open-ended request in order to obtain missing information or for clarification whenever necessary. Where possible, we extracted data relevant to each component centre of multi-centre studies separately.

\section{Management}

2.1 Forms

Data were extracted onto standard, simple forms.

\section{Scale-derived data}

We included continuous data from rating scales only if:

a) the psychometric properties of the measuring instrument had been described in a peer-reviewed journal (Marshall 2000); and b) the measuring instrument was not written or modified by one of the trialists for that particular trial; and

c) the measuring instrument was either (i) a self-report or (ii) completed by an independent rater or relative (not the therapist).

\section{Endpoint versus change data}

We preferred to use scale endpoint data, which typically cannot have negative values and is easier to interpret from a clinical point of view. Change data are often not ordinal and are very problematic to interpret. If endpoint data were unavailable we used change data.

\section{Skewed data}

Continuous data on clinical and social outcomes are often not normally distributed. To avoid the pitfall of applying parametric tests to non-parametric data, we aimed to apply the following standards to all data before inclusion: a) standard deviations and means are reported in the paper or obtainable from the authors; b) when a scale starts from the finite number zero, the standard deviation, when multiplied by two, is less than the mean (as otherwise the mean is unlikely to be an appropriate measure of the centre of the distribution, (Altman 1996); c) if a scale starts from a positive value (such as PANSS which can have values from 30 to 210) the calculation described above will be modified to take the scale starting point into account. In these cases skew is present if $2 \mathrm{SD}>(\mathrm{S}-\mathrm{S} \mathrm{min})$, where $\mathrm{S}$ is the mean score and $\mathrm{S}$ min is the minimum score. Endpoint scores on scales often have a finite start and end point and these rules can be applied. When continuous data are presented on a scale which includes a possibility of negative values (such as change data), it is difficult to tell whether data are skewed or not. Skewed data from studies of less than 200 participants were entered in additional tables rather than into an analysis. Skewed 
data pose less of a problem when looking at means if the sample size is large and were entered into syntheses.

\section{Common measure}

To facilitate comparison between trials, we intended to convert variables that can be reported in different metrics, such as days in hospital (mean days per year, per week or per month) to a common metric (e.g. mean days per month).

\section{Conversion of continuous to binary}

Where possible, efforts were made to convert outcome measures to dichotomous data. This could be done by identifying cut-off points on rating scales and dividing participants accordingly into 'clinically improved' or 'not clinically improved'. It was generally assumed that if there had been a 50\% reduction in a scale-derived score such as the Brief Psychiatric Rating Scale (BPRS, Overall 1962) or the Positive and Negative Syndrome Scale (PANSS, Kay 1986), this could be considered as a clinically significant response ( Leucht 2005a, Leucht 2005b). If data based on these thresholds were not available, we used the primary cut-off presented by the original authors.

\section{Direction of graphs}

Where possible, we entered data in such a way that the area to the left of the line of no effect indicates a favourable outcome for day hospital.

\section{Summary of findings table}

We anticipate including the following long-term main outcomes in a summary of Findings table.

\section{Service use}

1.1 Hospitalisation: mean number of days per month in hospital

1.2 Hospital admission across time

2. Death - suicide

3. Global state

3.1 Leaving the study early (lost to follow up)

3.2 Relapse

4. Social functioning

4.1 Employment - unemployed at end of study

5. Mental state: general symptoms

5.1. Not improved to a clinically meaningful extent (as defined in trial)

Within the Summary of findings table we assumed for calculation of the low risk groups that the lowest control risk applied to all data. We did the same for the assumption of the highest risk groups.

\section{Assessment of risk of bias in included studies}

Again working independently, authors ES, AS and FS assessed risk of bias using the tool described in the Cochrane Handbook for Systematic Reviews of Interventions (Higgins 2008). This tool encourages consideration of how the sequence was generated, how allocation was concealed, the integrity of blinding at outcome, the completeness of outcome data, selective reporting and other biases. We would have excluded studies where allocation was clearly not concealed.

Trials with high risk of bias (defined as at least three out of five domains categorized as 'No') were removed from the 'included' category.. If the raters disagreed, the final rating was made by consensus with the involvement of another member of the review group. Where inadequate details of randomisation and other characteristics of trials are provided, authors of the studies were contacted in order to obtain further information. Non-concurrence in quality assessment was reported.

\section{Measures of treatment effect}

1. Binary data

For binary outcomes we calculated a standard estimation of the fixed-effects risk ratio (RR) and its $95 \%$ confidence interval $(\mathrm{Cl})$. It has been shown that RR is more intuitive (Boissel 1999) than odds ratios and that odds ratios tend to be interpreted as RR by clinicians (Deeks 2000). For statistically significant results we calculated the number needed to treat to provide benefit/to induce harm statistic (NNTB/H) and its 95\% confidence interval (Cl) using Visual Rx (http://www.nntonline.net/) taking account of the event rate in the control group.

\section{Continuous data}

2.1 Summary statistic

For continuous outcomes we estimated a fixed-effect mean difference (MD) between groups. We preferred not to calculate effect size measures (standardised mean difference (SMD)). However, where scales were of such similarity to allow presuming there was a small difference in measurement, we calculated it and, whenever possible, we transformed the effect back to the units of one or more of the specific instruments.

\section{Unit of analysis issues}

1. Cluster trials

Studies increasingly employ 'cluster randomisation' (such as randomisation by clinician or practice) but analysis and pooling of clustered data poses problems. Firstly, authors often fail to account for intraclass correlation in clustered studies, leading to a 'unit of analysis' error (Divine 1992) whereby $p$ values are spuriously low, confidence intervals unduly narrow and statistical significance overestimated. This can cause type I errors (Bland 1997, Gulliford 1999).

Where clustering is not accounted for in primary studies, we presented data in a table, with $a^{*}$ ( ) symbol to indicate the presence of a probable unit of analysis error. In subsequent versions of this review we will seek to contact first authors of studies to obtain intraclass correlation coefficients for their clustered data and to adjust for this by using accepted methods (Gulliford 1999). Where clustering had been incorporated into the analysis of primary studies, we present these data as if from a non-cluster randomised study, but adjusted for the clustering effect.

We have sought statistical advice and have been advised that the binary data as presented in a report should be divided by a 'design effect'. This is calculated using the mean number of participants per cluster $(\mathrm{m})$ and the intraclass correlation coefficient (ICC) [Design effect $\left.=1+(m-1)^{\star} I C C\right]$ (Donner 2002). If the ICC was not reported it was assumed to be 0.1 (Ukoumunne 1999).

If cluster studies has been appropriately analysed taking into account intraclass correlation coefficients and relevant data documented in the report, synthesis with other studies would have been possible using the generic inverse variance technique. 


\section{Cross-over trials}

A major concern of cross-over trials is the carry-over effect. It occurs if an effect (e.g. pharmacological, physiological or psychological) of the treatment in the first phase is carried over to the second phase. As a consequence on entry to the second phase the participants can differ systematically from their initial state despite a wash-out phase. For the same reason cross-over trials are not appropriate if the condition of interest is unstable (Elbourne 2002). As both effects are very likely in severe mental illness, we will only use data of the first phase of cross-over studies.

3. Studies with multiple treatment groups

Where a study involved more than two treatment arms, if relevant, the additional treatment arms were presented in comparisons. Where the additional treatment arms were not relevant, these data were not reproduced.

\section{Dealing with missing data}

1. Overall loss of credibility

At some degree of loss of follow-up data must lose credibility (Xia 2007). For any particular outcome should more than $50 \%$ of data be unaccounted for, we did not reproduce these data or use them within analyses. If, however, more than $50 \%$ of those in one arm of a study were lost, but the total loss was less than $50 \%$, we marked such data with $\left({ }^{*}\right)$ to indicate that such a result may well be prone to bias.

\section{Binary}

In the case where attrition for a binary outcome is between 0 and $50 \%$ and where these data were not clearly described, data were presented on a 'once-randomised-always-analyse' basis (an intention-to-treat analysis). Those lost to follow up were all assumed to have the same rates of negative outcome as those who completed, with the exception of the outcome of death. A sensitivity analysis was undertaken testing how prone the primary outcomes were to change when 'completed' data only were compared to the intention-to-treat analysis using the above assumption.

\section{Continuous}

3.1 Attrition

In the case where attrition for a continuous outcome is between 0 and $50 \%$ and completer-only data were reported, we have reproduced these.

\subsection{Standard deviations}

\subsubsection{General}

Where there are missing measures of variance for continuous data but an exact standard error and confidence interval are available for group means, either ' $p$ ' value or ' $t$ ' value are available for differences in mean, we will calculate standard deviation value according to methods described in Section 7.7.3 of the Cochrane Handbook for Systematic Reviews of Interventions (Higgins 2008). If standard deviations were not reported and could not be calculated from available data, we asked authors to supply the data. In the absence of data from authors, we used the mean standard deviation from other studies.

3.2.2 Standard deviation mean number of days per month in hospital

For the primary outcome, mean number of days per month in hospital, if standard deviations were not reported and could not be calculated from available data, we asked authors for additional information. In the absence of data from authors, we calculated missing standard deviations using a regression analysis of standard deviation against mean, based on data from studies which did report these data.

\subsection{Last observation carried forward}

We anticipated that in some studies the method of last observation carried forward (LOCF) would be employed within the study report. As with all methods of imputation to deal with missing data, LOCF introduces uncertainty about the reliability of the results. Therefore, where LOCF data has been used in the trial, if less than $50 \%$ of the data had been assumed, we reproduced these data and indicated that they are the product of LOCF assumptions.

\section{Assessment of heterogeneity}

1. Clinical heterogeneity

We considered all included studies initially, without seeing comparison data, to judge clinical heterogeneity. We simply inspected all studies for clearly outlying situations or people which we had not predicted would arise. Should such situations or participant groups have arisen they were fully discussed.

\section{Methodological heterogeneity}

We considered all included studies initially, without seeing comparison data, to judge methodological heterogeneity. We simply inspected all studies for clearly outlying methods which we had not predicted would arise. Should such methodological outliers have arisen they were fully discussed.

\section{Statistical}

3.1 Visual inspection

We visually inspected graphs to investigate the possibility of statistical heterogeneity.

\subsection{Employing the 12 statistic}

Heterogeneity between studies was investigated by considering the $\mathrm{I}^{2}$ method alongside the $\mathrm{Ch} \mathrm{i}^{2}$ ' $\mathrm{p}$ ' value. The $\mathrm{I} 2$ provides an estimate of the percentage of inconsistency thought to be due to chance (Higgins 2003). The importance of the observed value of $\mathrm{I}^{2}$ depends on i. magnitude and direction of effects and ii. strength of evidence for heterogeneity (e.g. ' $p$ ' value from $\mathrm{Chi}^{2}$ test, or a confidence interval for $\mathrm{I}^{2}$ ).

12 estimate greater than or equal to $50 \%$ accompanied by a statistically significant $\mathrm{Chi}^{2}$ statistic, was interpreted as evidence of substantial levels of heterogeneity (Section 9.5.2 - Higgins 2008) and reasons for heterogeneity were explored. If the inconsistency was high and the clear reasons were found, data were presented separately.

\section{Assessment of reporting biases}

Reporting biases arise when the dissemination of research findings is influenced by the nature and direction of results (Egger 1997). These are described in Section 10 of the Cochrane Handbook for Systematic Reviews of Interventions (Higgins 2008). We are aware that funnel plots may be useful in investigating reporting biases but are of limited power to detect small-study effects. We did not use funnel plots for outcomes where there were ten or fewer studies, or where all studies were of similar sizes. In other cases, where funnel plots were possible, we sought statistical advice in their interpretation. 


\section{Data synthesis}

Where possible we employed a fixed-effect model for analyses. We understand that there is no closed argument for preference for use of fixed or random-effects models. The random-effects method incorporates an assumption that the different studies are estimating different, yet related, intervention effects. This does seem true to us, however, random-effects does put added weight onto the smaller of the studies - those trials that are most vulnerable to bias. It is for this reason we use the assumption-free fixed-effect model.

\section{Subgroup analysis and investigation of heterogeneity}

\section{Subgroup analyses}

We anticipated no sub-group analyses.

2. Investigation of heterogeneity

2.1 Unanticipated heterogeneity

Should unanticipated clinical or methodological heterogeneity be obvious we will simply state hypotheses regarding these for future reviews or versions of this review. We do not anticipate undertaking analyses relating to these.

\subsection{Anticipated heterogeneity}

We did not anticipate any heterogeneity.

\section{Sensitivity analysis}

\section{Implication of randomisation}

We aimed to include trials in a sensitivity analysis if they are described in some way as to imply randomisation. For the primary outcomes we included these studies and if there was no substantive difference when the implied randomised studies were added to those with better description of randomisation, then all data were employed from these studies.

\section{Assumptions for lost binary data}

Where assumptions had to be made regarding people lost to follow up (see Dealing with missing data) we compared the findings of the primary outcomes when we used our assumption compared with completer data only. If there was a substantial difference, we reported results and discuss them but continued to employ our assumption.

\section{RES ULT S}

\section{Description of studies}

\section{Results of the search}

\section{Original search - 2001}

The first version of this review (Marshall 2001) undertook a large search. The search was done by deriving a list of search terms from reading overviews of the field and consulting experts in day hospital care. The reference databases listed in Appendix 1 were searched.

\section{Update search - 2009}

The May 2009 update search of the Cochrane Schizophrenia Group's Register of Trials yielded 1104 references (from 565 studies). Initial screening reduced this figure to 28 references. After additional evaluation, 12 trials were selected for further inspection and full texts of articles were ordered.

\section{Included studies}

For substantive descriptions of studies please see Characteristics of included studies tables.

The original review, Marshall 2001, included eight trials. However, four of these did not meet the entry criteria for the present review (Bateman 1999, Dick 1985, Piper 1993, Tyrer 1979). Although all studies were randomised controlled trials, only four had data specifically about people with schizophrenia (Glick 1986, Linn 1979, Meltzoff 1966, Weldon 1979). Additional references from the search results have not contributed to the included studies. Thus the present review includes four studies.

\section{Length of trials}

The trials had follow up periods of three months (Weldon 1979), 12 months (Glick 1986), 18 months (Meltzoff 1966), and 24 months (Linn 1979). Three months would appear to be a short follow up period given that day care centres are directed at improving outcome in the long term for severely mentally ill people.

\section{Setting}

All studies were undertaken in the USA. Weldon 1979 and Glick 1986 were from the Payne Whitney Clinic of New York Hospital. The earlier study involved working with only people referred from inpatient wards and the latter from both in- and outpatient care. Meltzoff 1966 and Linn 1979 were both set within the Veterans Administration system of health care. Linn 1979 was multicentre with 10 hospitals taking place (California - two, Texas - three, Illinois - one, Florida - one, lowa - one, Minnesota - one, Tennessee - one).

\section{Participants}

Linn 1979 recruited people with schizophrenia who had just been discharged from inpatient care. This trial was conducted in Veterans' Administration hospitals and was restricted to men only. The diagnosis of schizophrenia was confirmed by a psychiatrist using unspecified criteria. Meltzoff 1966 was also a Veterans' Administration trial. This trial recruited men "with a neuropsychiatric disability" who had spent time in hospital, and were not suicidal or violent. Ninety-one per cent had schizophrenia, though it was unclear how this diagnosis was made. Weldon 1979 recruited people with schizophrenia who had recently been discharged from inpatient care and had no history of self-harm, violent behaviour or drug abuse. It was unclear how the diagnosis of schizophrenia was made. In contrast to the other two trials, the majority of participants were women (21 out of 30). Glick 1986 recruited people with schizophrenia or major affective disorders who were referred from the inpatient wards of a large psychiatric hospital. Participants were required to have residual psychotic symptoms and a need for ongoing treatment.

\section{Study size}

No study reported a pre-trial power calculation. The trials in descending order of size were: Linn 1979 ( $n=162)$, Glick 1986 ( $n=79)$, Meltzoff $1966(n=80)$ and Weldon $1979(n=30)$.

\section{Interventions}

4.1 Day hospital

We think that Linn 1979, Meltzoff 1966 and Weldon 1979 fall into the same broad category of 'day treatment centres'. In Linn 1979 there were 10 Veterans' Administration day care centres that aimed to enhance social functioning for the long term by offering a place to socialise and engage in productive activities. The centres employed 
social workers and physicians and offered: recreational activities, group therapy, counselling, occupational therapy and medication follow up. For Meltzoff 1966 the day care centre offered individual and group psychotherapy and medication. The staff to patient ratio was not reported. In Weldon 1979 the day care centre group received group therapy, medication and structured activities. The staff to patient ratio was 1:2.5.

In Glick 1986, however, the day hospital aimed to enhance social functioning in chronic patients by offering a place to socialise and engage in productive activities. The hospital employed social workers and physicians and offered: recreational activities, group therapy, counselling, occupational therapy, and medication follow up. Staff members acted as a case managers, managed one-toone intervention and coordinated patients care plans. Existing inpatient staff were used to provide daily recreational therapy/ weekly dance therapy. Inpatient medical staff provided ongoing medical management. The "transitional treatment staff" were also part of inpatient unit staff and were therefore familiar with all patients before their initiation into program. We feel justified in categorising this differently to the other three trials and calling it a 'transitional day hospital'.

\subsection{Outpatient care}

Control treatments for each study were as follows: Linn 1979 and Glick 1986 provided outpatient drug management from the same physicians as worked in the day care centres, no other aftercare was offered. In Meltzoff 1966 participants received standard outpatient care and in Weldon 1979 participants received psychotherapyoriented outpatient care, but also offered medication.

\section{Outcomes}

\subsection{General remarks}

Data were available for the outcomes of service use (admitted to hospital), global state (lost to follow up), social functioning (employment) and death. The outcomes of admitted to hospital and lost to follow up had been pre-stipulated as the primary outcomes of this review.

\subsection{Outcome scales}

Details of the scales that supplied usable data for this review are shown below. Reasons for exclusion of data from other scales are given under 'Outcomes' in the 'Characteristics of included studies

\subsubsection{Global functioning}

5.2.1.1 Global Assessment scale (GAS) (Endicott 1976)

This interviewer-rated scale is used to make a global assessment of the severity of psychiatric disturbance. Higher scores indicate better functioning.

\subsubsection{Mental state}

5.2.2.1 Brief Psychiatric Rating Scale (BPRS) (Overall 1962)

This interviewer-rated scale assesses the severity of psychiatric symptoms. The original scale has 16 items, but a revised 18 -item scale is commonly used. Each item is defined on a seven-point scale from 'not present' to 'extremely severe', scoring from zero to six or one to seven. Scores can range from 0 to 126, with high scores indicating more severe symptoms.

\subsubsection{Psychiatric Evaluation Form (PSE) (Endicott 1972)}

This interviewer-rated scale is used to evaluate the severity of psychiatric symptoms. Higher scores indicate more severe symptoms.

\subsubsection{Symptom Check List (SCL-90) (Derogatis 1977)}

This self-report symptom inventory consists of 90 items for the measurement of psychopathology in psychiatric and medical patients (in its earliest form it was the 59-item Hopkins Symptom Checklist). Participants are asked to rate distress due to particular symptoms on a five point scale from one (not at all) to five (extreme) over the previous 14 days.

\subsubsection{Social functioning}

5.2.3.1 Community Adaption Scale (CAS) (Roen 1966)

This interviewer-rated scale assesses social functioning. Higher scores indicate lower functioning.

\subsubsection{SAS (Weissman 1981)}

This interviewer-rated scale assesses social functioning. Higher scores indicate poorer social functioning.

\subsubsection{Social Dysfunction Rating Scale (SDRS) (Linn 1969)}

This interviewer-rated scale consists of 21 items assessing social functioning. Each item is rated on a six-point scale with higher scores indicating poorer social functioning.

\subsection{Missing outcomes}

No usable data were available for quality of life, adverse events, burden on relatives, mean monthly cost of all care and satisfaction with care.

\section{Excluded studies}

For substantive descriptions of studies please see Characteristics of excluded studies tables.

Sixty-five studies were excluded in the original review (Marshall 2001), 43 were non-randomised studies and 22 were randomised but not of relevance. The non-randomised studies consisted of: two surveys (without comparison groups), 11 surveys with comparison groups, two uncontrolled follow up studies, four 'before and after' comparisons, eight case-control or retrospective cohort studies, and 16 quasi-experimental designs (i.e. comparative trials without randomisation). The excluded randomised controlled trials consisted of: one trial of admission to hospital versus outpatient care, 11 trials of acute day hospital care versus admission, five trials of day hospital care (to reduce duration of admission) versus admission, four trials of enhanced day hospital care (enhanced by cognitive therapy, problem solving, group therapy and self-control therapy respectively) versus standard day hospital care, and one trial that could not be classified (Guy 1969) as the day hospital in question functioned simultaneously as a day care centre, day treatment programme and transitional day hospital. We looked at this study in the light of this updated version. We excluded this study as participants were "in need of inpatient care" and can not be ascertained as "not acutely ill".

The original review (Marshall 2001) included eight studies which were all re-evaluated for the present update. Out of these four studies had to be excluded as their focus was on people with depression, anxiety, personality disorder, neurotic disorders and not people with schizophrenia (Bateman 1999, Dick 1991, Piper 1993, Tyrer 1979).

Seven trials, which had been on awaiting assessment list in the earlier version of this review were also evaluated. Five studies had to be excluded as being non-randomised trials (Bertrand 1973, McDonnell 1977, Newton 1983, Prior 1998, Vietze 1976), one 
randomised control trial (Skoda 1983) was excluded as a study for people with neuroses not schizophrenia and one study (Pang 1985) used inpatients as a control group, not day hospital versus outpatient care.

The Priebe-MECCA-2002 randomised controlled trial, ongoing at the time of the earlier version of this review, was excluded as it was a package of care within which outcomes were fed back to patients and was not day hospital versus outpatient care. Priebe 2006 is a randomised trial testing day hospital versus inpatient care and Priebe 1999 is a randomised trial testing treatment changes according to patient wishes, not day hospital versus outpatient care. Another randomised controlled trial (Reynolds 2004) was excluded as a trial testing transitional discharge model versus referral to locally-based nurses, not the day hospital versus outpatient care and finally Takano 1995 and Tsukahara 1998 were not randomised.
In total eighty-seven studies were evaluated and eighty-two were excluded in the present review.

\section{Awaiting assessment}

After extensive searching only one study, Dal Santo 2004, remains on the awaiting assessment list, the full text of the article continues to be sought.

\section{Ongoing studies}

As far as we know there are no ongoing studies of relevance.

\section{Risk of bias in included studies}

For multi-centre trials providing data for single centres, we did not assess the risk of bias for each centre. Our judgments regarding the overall risk of bias in individual studies are illustrated in Figure 1.

Figure 1. Methodological quality summary: review authors' judgements about each methodological quality item for each included study.

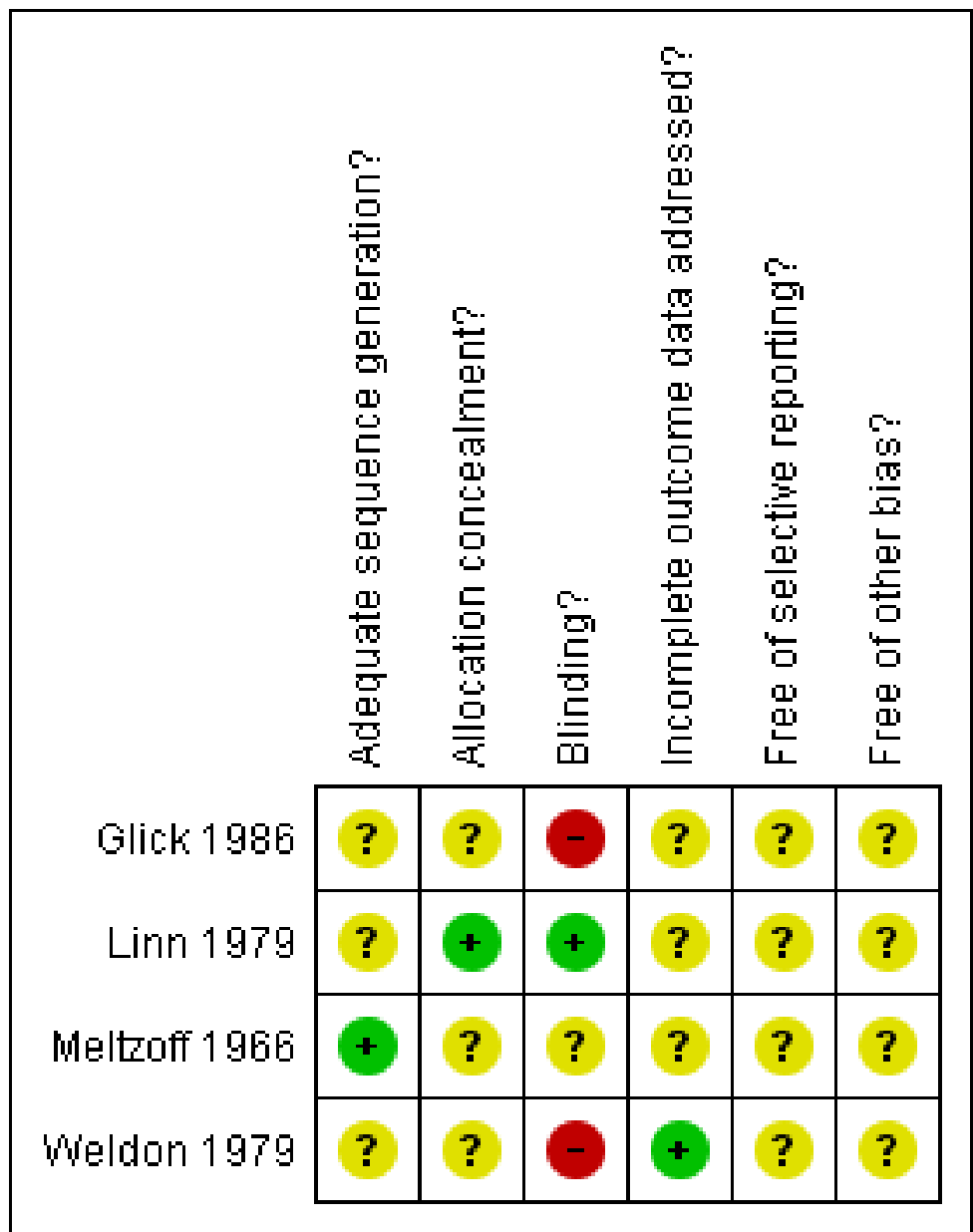

\section{Allocation}

Four studies were stated to be randomised but only Meltzoff 1966 provided descriptions of the methods used to generate the sequence with 80 cards shuffled by use of random number. The other studies, Linn 1979, Weldon 1979, and Glick 1986, therefore, are classified as of 'unclear' quality with a moderate risk of selection bias and of overestimate of positive effect as no description of the methods used to generate the sequence had been provided.

Regarding allocation concealment, only two trials provided description of allocation concealment. Linn 1979 randomised by sealed envelope and Meltzoff 1966 by a random numbers table. Data from Weldon 1979 and Glick 1986 did not specify the method 
of concealment and, therefore, may be subject to bias. It is known that poor reporting of randomisation increases the chances of 'significant' outcomes (Schulz 1995).

\section{Blinding}

We classified blinding in respect only to primary outcomes. Due to the nature of the interventions (day hospital versus outpatient care), we assumed participants and clinicians were not blind to treatment assignment. We also assumed that primary outcomes were likely to be influenced by participant and clinician's lack of blinding, as the knowledge of treatment allocation could determine both performance and attrition bias at a level which is difficult to predict/quantify. We did not, however, consider the primary outcomes as interviewer mediated, so we assume that lack of interviewer blinding would produce less detection bias. Therefore all studies providing primary outcome data are classified as of 'unclear' quality with a moderate risk of performance and attrition bias. This gathers further potential for overestimate of positive effects and underestimate of negative ones.

We report blinding to secondary outcomes in the risk of bias table but we do not account for it in the global rating of studies' risk of bias. Again, if a secondary outcome was clinician/participant mediated, we rated it as 'unclear'. If it was interviewer rated, we assessed it according to information provided in the study.

In Linn 1979 there were professional, independent, raters. Study authors affirm that collection of outcome data was indeed blinded. Weldon 1979 and Glick 1986 were not blinded by design, whereas in Meltzoff 1966 it was unclear whether blinding was successful even when authors stated that research personnel had no dealing with patients.

\section{Incomplete outcome data}

Follow up rates were as follows: Weldon $1979100 \%$ at three months, Glick 1986 67\% at 12 months, Meltzoff $196686.3 \%$ at 18 months and Linn $197985 \%$ at 24 months. Weldon 1979 was judged as low risk of attrition bias because there was no loss to follow up in this study.

Glick 1986, Linn 1979, and Meltzoff 1966 were rated as 'unclear' with a moderate risk of attrition bias. They either did not address this issue (Glick 1986 - the reasons for leaving the study are not mentioned) or presented insufficient information (Linn 1979 major reason for leaving the study was moving from area but data was not reported by group allocation, Meltzoff 1966 - missing data on 29 interviews reported but not explained) of attrition/exclusions to permit judgment.

\section{Selective reporting}

We have no trial protocols. In the published papers the methods described are consistent with outcomes reported. One trial failed to collect outcome data that could be analysed on an intentionto-treat basis. Meltzoff 1966 excluded people after randomisation, who had either failed to engage in treatment or were in hospital at the time of follow up. All studies were rated as of 'unclear' quality with a moderate risk of selective reporting.

\section{Other potential sources of bias}

Although, we found no obvious evidence of other bias occurring and all trials were publicly funded, we rated as 'unclear' our judgment for other potential sources of bias. No declaration of interest was made by authors, and we assumed there was none to be made. However, some study authors were active supporters of the day hospital care model across the scientific community and clinical world. This raises the issue on how researcher beliefs could affect the entire process of evaluating an intervention in a randomised clinical trial. Although conscious of this issue, we decided not to make any attempt in rating it as it is very difficult to judge and erroneous quantification could drive bias into our conclusions.

\section{Effects of interventions}

See: Summary of findings for the main comparison DAY HOSPITAL versus OUT-PATIENT CARE for people with schizophrenia near or on discharge

\section{COMPARISON 1. DAY HOSPITAL versUS OUTPATIENT CARE - NEAR} OR ON DISCHARGE

1.1 Primary outcomes

1.1.1 Service use

1.1.1.1 Hospitalisation: mean number of days per month in hospital Only Linn 1979 ( $n=162$, day treatment centre) reported data for this important outcome. This trial suggested that that people allocated to day centres spent significantly fewer days in inpatient care over a two-year period (day centre $77.9, \mathrm{n}=80$ vs outpatient $95.9, \mathrm{n}=82$ ). These data are not, however, accompanied by $p$-value, variance or confidence intervals.

\subsubsection{Not remaining in contact with psychiatric services}

The nearest outcome to our second desired primary outcome was: Global state - Leaving the study early (lost to follow up - day treatment centres / transitional day hospital). We found no clear difference between day hospital and outpatient care for the outcome of 'lost to follow up' ( $n=147,3$ RCTs, RR at 6 months 0.97 $\mathrm{Cl} 0.48$ to 1.95 'moderate' quality GRADE, Summary of findings for the main comparison; $\mathrm{n}=117,2 \mathrm{RCTs}$, RR at 12 months $0.97 \mathrm{Cl} 0.48$ to 1.95 , 'low' quality GRADE, Summary of findings for the main comparison).

\subsection{Secondary outcomes}

1.2.1 Death - suicide and all causes - day treatment centres One small study (Weldon 1979, $n=30$ ) reported on mortality at three months with no deaths in either group.

\subsubsection{Service use}

1.2.2.1 Admitted to hospital across time - day treatment centres By six months about $20 \%$ of both groups had been admitted $(n=110$, 2 RCTs, RR $0.58 \mathrm{Cl} 0.26$ to 1.33 , 'moderate' quality GRADE, Summary of findings for the main comparison). By the one-year follow up this proportion increased but was slightly different between the two groups ( $\mathrm{n}=242$, 2 RCTs, RR $0.73 \mathrm{Cl} 0.54$ to 1.00 , 'low' quality GRADE, Summary of findings for the main comparison). After that period a clear difference in favour of day hospital is apparent but these data are heterogeneous ( $n=242,2$ RCTs, RR $0.71 \mathrm{Cl} 0.56$ to $0.89, \mathrm{I}^{2}$ $=74 \% \mathrm{P}=0.05$, 'moderate' quality GRADE, Summary of findings for the main comparison) and, according to our protocol should not be summated. We wanted to display the findings all together and are unable to restrict synthesis to the first two subgroups.

\subsubsection{Global state}

\subsubsection{Number lost to follow up}

We have reported this outcome, please see above 1.1.1.2 Service use: Not remaining in contact with psychiatric services. 
1.2.3.2 Average score (GAS, high score $=$ good $)$ - transitional day hospital

All data originate from Glick 1986 (data from schizophrenia subgroup only). This study reports no difference between the two interventions with ( $n=37,1 \mathrm{RCT}$, MD by 6 months $-7.9 \mathrm{Cl}-15.68$ to -0.12 ; MD by/at 12 months $-4.31 \mathrm{Cl}-15.24$ to 6.62 ).

\subsubsection{Social functioning}

1.2.4.1 Average scores (CAS - day treatment centres, SAS transitional day hospital)

Weldon 1979 reported no significant difference in social functioning as measured by Community Adaption Scale (CAS) by six months ( $n=30,1$ RCT, MD $-0.03 \mathrm{Cl}-0.30$ to 0.24 ). Glick 1986 found a borderline significant difference at six months in favour of the people allocated to outpatient care ( $n=37,1$ RCT, MD $0.36 \mathrm{Cl}-0.07$ to 0.79 ) but even this difference in social functioning as measured by SAS was lost by 12 months ( $n=37,1$ RCT, MD $0.17 \mathrm{Cl}-0.25$ to 0.59 ). Linn 1979 $(n=162)$ reported a significant time by group difference on social functioning (SDRS) in favour of the day centre group but univariate comparisons at 6, 12, 18 and 24 months were not significant. These data could not be added to the meta-analysis, as numbers at each follow up point, standard deviations, $p$-values and confidence intervals were not reported.

1.2.4.2 Unemployed - day treatment centres

At six months Weldon 1979 reported an effect favouring the day hospital group ( $n=30,1 \mathrm{RCT}, \mathrm{RR} 0.04 \mathrm{Cl} 0.00$ to $0.62, \mathrm{P}=0.02$, 'low' quality GRADE, Summary of findings for the main comparison), but by 12 months one other study, Meltzoff 1966, found no difference between the day hospital and outpatient groups ( $n=80,1$ RCT, RR unemployed $0.86 \mathrm{Cl} 0.69$ to 1.06 , 'moderate' quality GRADE, Summary of findings for the main comparison).

\subsubsection{Mental state}

1.2.5.1 Average scores (PEF - transitional day hospital, POMS, SCL 90 - day treatment centres)

Weldon 1979 reported no significant difference in mental state by six months using the Symptom Check List (SCL-90) ( $n=30,1$ RCT, MD $0.31 \mathrm{Cl}-0.20$ to 0.82 ). This same study reported data on Profile of Mood States (POMS) and found no difference between day hospital and outpatient groups ( $n=30,1 \mathrm{RCT}, \mathrm{MD} 16.93 \mathrm{Cl}-20.49$ to 54.35). One other small trial found no significant difference in mental state between treatment and control groups by six months ( $n=37,1$ RCT, $M D$ on PEF $0.52 \mathrm{Cl}-0.02$ to 1.06 ) or by one year ( $n=37,1 \mathrm{RCT}$, MD on PEF $0.15 \mathrm{Cl}-0.46$ to 0.76$)$.

Linn 1979 ( $n=162$ ) reported a significant time by group interaction (ANOVA) in favour of day centre participants (at six months day centre mean 37.4 control $38.1 ; 12$ months day centre 36.0 , control $36.6 ; 18$ months day centre 35.4 , control $36.3 ; 24$ months day centre 31.3 , control 38.4 ). In point by point comparisons only the final difference at 24 months was significant $(p<0.01, F=8.08$ ). These data could not be added to the meta-analysis as numbers of people at each follow up point and standard deviations were not reported.

\subsubsection{Economic}

Weldon $1979(n=30)$ and Meltzoff $1966(n=80)$ did not report any economic data.

1.2.6.1 Costs of psychiatric hospital care - day treatment centres Linn 1979 ( $n=162$ ) reported a 32.8\% increase in mean monthly cost of psychiatric care in the day centre group, but these were based on the costs of inpatient and day treatment centre care only, and did not include the costs of outpatient care (day centre $\$ 246$, outpatient
\$185). The difference was reported as not significant but this finding was difficult to evaluate as no standard deviations were presented.

\subsubsection{Overall costs of running the programme}

Linn 1979 ( $n=162$, day treatment centres) reports that the overall average cost for two years per person is $\$ 5,895$ (day hospital) versus $\$ 4,437$ (outpatient care). Glick 1986 ( $n=37$, sub-group, transitional day hospital) estimates costs for the whole programme as considerably less expensive for the outpatient programme ( $\$ 10,000$ annual cost) compared with the costs of running the day hospital $(\$ 100,000$ annual cost $)$.

\section{DISC USSION}

\section{Summary of main results}

\section{Service use}

1.1 Hospitalisation: mean number of days per month in hospital Our primary outcome was time in hospital. Linn 1979 ( $n=162$, day treatment centre) reported these data and suggested that people allocated to day centres spent significantly fewer days in inpatient care over a two-year period but data were impossible to present in graphical form. We did also find some information in Meltzoff 1966 ( $n=80$, day treatment centre) in which the author reports the total amount of time spent in hospital by people allocated to out patient care was 172.5 man-months in contrast to 102 manmonths for day treatment centre $\left(X^{2}=15.57, p<0.001\right)$. They note that the savings of 70.5 man-months (or approximately 2200 days) was accrued within eighteen months of the study period. Again these data are intriguing and important but difficult to generalise to modern times, not well enough reported to synthesise, are from an analysis of only those who completed the study and finally from a single small trial. The impression is, however, that day hospital does reduce time in inpatient care.

\subsection{Not remaining in contact with psychiatric services}

For our second key outcome, we found no clear difference between day hospital and outpatient care for the outcome of 'lost to follow up' ( $\mathrm{n}=147,3 \mathrm{RCTs}$, RR at 6 months $0.97 \mathrm{Cl} 0.48$ to $1.95 ; \mathrm{n}=117$, 2 RCTs, RR at 12 months $0.97 \mathrm{Cl} 0.48$ to 1.95). These data are heterogeneous $(12=53 \%, P=0.14)$ but there is the impression that the day care does not really effect attrition from services. Glick 1986, the transitional service, is combined with the other two day treatment centres and may add to the heterogeneity as it does seem to be less positive than the other two studies. The text of Glick 1986 suggested that transitional day hospital care was superior to out patient care in keeping people engaged in treatment. However, their sub-analysis indicated that this effect was mainly due to better engagement of people with affective disorders, not schizophrenia.

1.3 Service use: Admitted to hospital across time - day treatment centres

Results suggest that day hospital care reduces rate of inpatient admissions. This finding becomes statistically significant at, and beyond, 12 months. The data are somewhat heterogeneous at 12 months $(12=60 \%, P=0.11)$ but more clearly so beyond that period $\left(1^{2}\right.$ $=74 \% \mathrm{P}=0.05)$. We do not see clear reasons for this, except perhaps that the latter of the two studies was undertaken in a time when community care was well into the process of being implemented. Thirteen years earlier, at the time of the first study, the control group may not have had the additional community resources that one would hope would be available for people in distress and that may have been available in the late 1970s. 
2. Death - suicide and all causes - day treatment centres

Only Weldon 1979 ( $n=30$ ) reported on mortality at three months (no deaths in either group) and this outcome was not reported by any of the other trials. For this rare outcome to be investigated in any study the size of the trial would have to be considerable. We have no evidence that day hospital care helps or harms in terms of death.

\section{Global state}

We have reported one of the global state outcomes above - please see 1.2 Service use. Not remaining in contact with psychiatric services.

3.1 Global state: 2. Average score (GAS, high score = good) transitional day hospital

Only Glick 1986 ( $n=37$, sub-group) reported an average score for global state. By six months there was about an eight-point decline for those allocated to day hospital and this just reached conventional levels of statistical significance. By 12 months this difference was only about four points and not significant. In any event we are unclear of the validity and clinical meaning of these data. We do not think that participants who provided these data were all who were originally randomised, and are unsure if these are really continuous data (and not ordinal). Even if valid the meaning of eight or four points difference is problematic to ascertain.

\section{Social functioning}

3.1 Average scores (CAS - day treatment centres, SAS - transitional day hospital)

Social functioning was measured by two different trials using two different scales. Data are not conclusive.

\subsection{Unemployed - day treatment centres}

At six months Weldon $1979(n=30)$ reported an effect favouring the day hospital group (RR $0.04 \mathrm{Cl} 0.00$ to $0.62, \mathrm{P}=0.02$ ), but by 12 months one other study (Meltzoff 1966, $n=80$ ), found no difference between the day hospital and outpatient groups (RR unemployed $0.86 \mathrm{Cl} 0.69$ to 1.06$)$.

Data from two small trials (total $n=110$ ) tended to suggest that this risk of unemployment was reduced by day hospital care. Synthesising the two results is inadvisable $\left(\mathrm{Tau}^{2}=9.79, \mathrm{Chi}^{2}=10.95\right.$, $\mathrm{df}=1, \mathrm{P}=0.0009, \mathrm{I}^{2}=91 \%$ ) but both trials do seem generally supportive of the idea that day hospital care can help people be employed. However, the trial with the most favourable result for day hospital care was set up in such way that it provided vocational therapy, including paid employment to participants whereas the control out patient care package did not. The second trial (Meltzoff $1966, n=80)$ did also find in favour of the day care $(n=80, R R 0.86 \mathrm{Cl}$ 0.69 to 1.06 ) although not to a statically significant extent. This is again, another area for additional research.

\section{Mental state}

5.1 Average scores (PEF - transitional day hospital, POMS, SCL 90 day treatment centres)

Three different small trials reported on mental state using three different scales. All findings suggest that there was no clear advantage or disadvantage for use of either package of care.

\section{Economic}

Economic data were few, reported in different ways and impossible to bring up to date. There was the suggestion, however, that day hospital care is more expensive both to establish and to run. This, of course, is offset by the suggested saving in inpatient care - but these calculations were not reported in any study. We remain unclear if day hospital care does save money.

\section{Overall completeness and applicability of evidence}

It is always possible that we may have failed to identify some studies. However, we have tried to be comprehensive as possible in our search strategy and thorough in our consideration of everything identified. There were losses of data from the studies we have identified. People did not have data recorded once they left the study, some data were presented without variance and completer only data were reported in several studies. Should these trials be reporting today it is likely that a more complete data set would be available. We have already alluded to the possibility that some data are difficult to apply in the context of modern services. The oldest trial was undertaken over four decades ago when the standard care for people receiving outpatient care may not have been as it is today. This is, however, open to dispute as most people who suffer from schizophrenia live in countries where the additional resources beyond that standard care outpatient services may not be sophisticated. We do feel that the results we are presenting should be interpreted with caution but not that they are inapplicable.

\section{Quality of the evidence}

The quality of the four trials providing data was not optimal (Figure 1). Sequence generation is often not made explicit, allocation concealment is unclear, blinding is probably impossible most of the time and we are not sure of whether incomplete outcome data has been well-addressed or that the studies were truly free of selective reporting. We are, of course, judging these pioneering trials by standards of today. The reporting of methods was not great but at least these trialists did attempt to undertake most difficult trials for important questions. The quality of methods would leave us needing to exercise caution but we do not feel that it should lead us to dismiss the important findings this review points towards.

\section{Potential biases in the review process}

The search may have failed to identify trials and, as with most electronic searches, is most likely to find studies from high-income countries. The studies we identified are small and there is also the potential for publication bias or small study biases creeping into the review. We have no protocols for the studies in this review so are not clear if the reports we have identified really report all data or a selection of the total results. We have tried to be as objective as possible selecting and extracting data, summarising them and undertaking the syntheses and write up. We welcome comments on biases we may have inadvertently introduced. We are not aware of any prior beliefs that would have influenced our production of this review.

\section{Agreements and disagreements with other studies or reviews}

This review substantially updates and improves past work. It does, however, largely agree with findings from previous versions (Marshall 2001) but has, perhaps, put less emphasis on positive findings. This is probably because of the new risk of bias table function of this version of RevMan. 


\section{AUTHORS' CONCLUSIONS}

\section{Implications for practice}

1. For people with schizophrenia

Currently the data to support the idea that day hospital or outpatient care helps avoid admission is not strong. There are, however, weak suggestions, that after a protracted period, day hospital care may help a person avoid coming into inpatient care. The person with schizophrenia will have to balance the implications of attending the day hospital, and all that entails for the deferring hospitalisation. We have no data to report on satisfaction with care or quality of life and what limited data there are on mental state and social functioning are equivocal.

\section{For clinicians}

Day hospital may help people in ways that have not been measured in these studies. On the other hand, it is perfectly feasible that attendance at such institutions could be restricting and stigmatising. The data in the studies reported in this review are really limited in helping support a blanket policy but have a suggestion that there may be some avoidance of readmission after a period of time. Clinicians intending to make use of day treatment programmes need to consider how far the inconvenience is balanced by the (somewhat weak) evidence for its effectiveness. In several countries day hospitals have been partially superseded by case management approaches and vocational rehabilitation programmes.

\section{For policy makers}

Policy makers need to consider how far the cost of providing day hospital care can be justified. Data on cost is very poor and out of date. Where day hospital facilities are being used to provide day programmes, clinicians and policy makers should consider whether these resources would be better deployed offering a treatment of more proven effectiveness.

\section{Implications for research}

1. General

This review highlighted the need for the improvement of quality of reporting research findings. The trials are old and all predate the first CONSORT statement by at least a decade (Begg 1996). If they had been able to anticipate CONSORT we would have had more data to use for this review. Certainly all new studies should closely comply with the minimum standards of CONSORT (Altman 2001).

\section{Specific}

We think that this review has demonstrated that there has not been enough basic research comparing day hospital care with outpatient care and that more trials are justified. We suggest a design taking good features from each of the studies we have scrutinized for this review (Table 1). Future research in this area needs to: a) provide a clear definition of 'treatment refractory outpatient'; b) define the ingredients of a 'day hospital'; c) compare day hospitals against clearly a described outpatient treatment; and d) carry out a careful analysis of cost effectiveness. It would be desirable for future trials in this area to be on a larger scale.

\section{ACKNOWLEDGEMENTS}

Previous versions of this review (Marshall 2001) have been supported by Guild Community Healthcare Trust, UK; NHS Health Technology Assessment - grant no. 96/41/3, UK. We would like to thank the substantial contribution of Max Marshall, Ruth Crowther and Peter Tyrer to the earlier versions of this review. Also, the staff at the Cochrane Schizophrenia Group (CSG) in Nottingham, UK are acknowledged for all their practical help and spiritual support during our review process. 


\section{RE F E R E N C E S}

\section{References to studies included in this review}

Glick 1986 \{published data only\}

* Glick ID, Fleming L, DeChillo N, Meyerkopf N, Jackson C, Muscara D, Good-Ellis M. A controlled study of transitional day care for non-chronically-ill patients. American Journal of Psychiatry 1986;143:1551-6.

\section{Linn 1979 \{published data only\}}

* Linn MW, Caffey EM, Klett CJ, Hogarty GE, Lamb HR. Day treatment and psychotropic drugs in the aftercare of schizophrenic patients: A veterans administration cooperative study. Archives of General Psychiatry 1979;36:1055-66.

\section{Meltzoff 1966 \{published data only\}}

* Meltzoff J, Blumenthal RL. The day treatment center: principles, application and evaluation. Springfield, Ill.: Charles C Thomas, 1966.

\section{Weldon 1979 \{published data only\}}

* Weldon E, Clarkin J, Hennessy JJ, Frances A. Day hospital versus outpatient treatment: a controlled study. Psychiatric Quarterly 1979;51:144-50.

\section{References to studies excluded from this review}

Austin 1976 \{published data only\}

* Austin NK, Liberman RP, King LW, De Risi WJ. A comparative evaluation of two day hospitals. Goal attainment scaling of behaviour therapy vs. milieu therapy. Journal of Nervous and Mental Disease 1976;163:253-62.

Azim 1978 \{published data only\}

* Azim HF, Weiden TD, Ratcliffe WD, Nutter RW, Dyck RJ, Howarth BG. Current utilization of day hospitalization. Canadian Psychiatric Association Journal 1978;23:557-66.

Barkley 1989 \{published data only\}

* Barkley AL, Fagen K, Lawson JS. Day care: can it prevent readmission to a psychiatric hospital?. Psychiatric Journal of the University of Ottawa 1989;14:536-41.

\section{Basker 1986 \{published data only\}}

* Basker E, Turel M. The day hospital: a comparative study of an alternative to full psychiatric hospitalization. Israel Journal of Psychiatry \& Related Sciences 1986;23:287-96.

\section{Bateman 1999 \{published data only\}}

Bateman A, Fonaghy P. Effectiveness of partial hospitalization in the treatment of borderline personality disorder: a randomized controlled trial. American Journal of Psychiatry 1999;156(10):1563-9.

Beigel 1970 \{published data only\}

* Beigel A, Feder SL. Patterns of utilization in partial hospitalization. American Journal of Psychiatry 1970;126:101-8.
Bertrand 1973 \{published data only\}

Bertrand J, Lisin P. Experiment with hospital day care in Belgium. Acta Psychiatrica Belgica 1973;73(1):53-65.

Boath 1999 \{published data only\}

* Boath E, Cox J, Lewis M, Jones P, Pryce A. When the cradle falls: the treatment of postnatal depression in a psychiatric day hospital compared with routine primary care. Journal of Affective Disorders 1999;53(2):143-51.

Bowman 1983 \{published data only\}

* Bowman EP, Shelley RK, Sheehy-Skeffington A, Sinanan K. Day patient versus in-patient: factors determining selection of acutely ill patients for hospital treatment. British Journal of Psychiatry 1983;42:584-7.

\section{Bradshaw 2000 \{published data only\}}

* Bradshaw W. Integrating cognitive-behavioral psychotherapy for persons with schizophrenia into a psychiatric rehabilitation program: results of a three year trial. Community Mental Health Journal 2000;36(5):491-500.

Brook 1973 \{published data only\}

* Brook BD. Crisis hostel: an alternative to psychiatric hospitalization for emergency patients. Hospital \& Community Psychiatry 1973;24:621-4.

Carey 1990 \{published data only\}

* Carey MP, Carey KB, Meisler AW. Training mentally ill chemical abusers in social problem solving. Behavior Therapy 1990;21(4):511-19.

Case 1991 \{published data only\}

${ }^{*}$ Case N. The dual-diagnosis patient in a psychiatric day treatment program: a treatment failure. Journal of Substance Abuse Treatment 1991;8:69-73.

Comstock 1985 \{published data only\}

* Comstock BS, Kamilar SM, Thornby JI, Ramirez JP, Kaplan HB. Crisis treatment in a day hospital. Impact on medical careseeking. Psychiatric Clinics of North America 1985;8:483-500.

Creed 1989 \{published data only\}

${ }^{*}$ Creed F, Anthony P, Godbert K, Huxley P. Treatment of severe psychiatric illness in a day hospital. British Journal of Psychiatry 1989;154:341-7.

Creed 1990 \{published data only\}

${ }^{*}$ Creed F, Black D, Anthony P, Osborn M, Thomas P, Tomenson B. Randomised controlled trial of day patient versus inpatient psychiatric treatment. BMJ 1990;300:1033-7.

Creed 1991 \{published data only\}

${ }^{\star}$ Creed F, Black D, Anthony P, Osborn M, Thomas, Franks D, Polley R, Lancashire S, Saleem P, Tomenson B. Randomised controlled trial of day and in-patient psychiatric treatment. 2. Comparison of two hospitals. British Journal of Psychiatry 1991;158:183-9. 


\section{Creed 1997 \{published data only\}}

* Creed F, Mbaya P, Lancashire S, Tomenson B, Williams B, Holme S. Cost effectiveness of day and in-patient psychiatric treatment. BMJ 1997;314:1381-5.

\section{Dick 1985 \{published data only\}}

* Dick P, Cameron L, Cohen D, Barlow, Ince A. Day and full time psychiatric treatment: a controlled comparison. British Journal of Psychiatry 1985;147:246-9.

Dick P, Ince A, Barlow M. Day treatment: suitability and referral procedure. British Journal of Psychiatry 1985;147:250-3.

\section{Dick 1991 \{published data only\}}

Dick PH, Sweeney ML, Crombie IK. Controlled comparison of day-patient and out-patient treatment for persistent anxiety and depression. British Journal of Psychiatry 1991;158:24-7.

\section{Drake 1994 \{published data only\}}

* Drake RE, Becker DR, Biesanz JC, Torrey WC, McHugo GJ, Wyzik PF. Rehabilitative day treatment vs. supported employment. I. Vocational outcomes. Community Mental Health Journal 1994;30:519-32.

\section{Ettlinger 1972 \{published data only\}}

* Ettlinger RA, Beigel A, Feder SL. The partial hospital as a transition from inpatient treatment: a controlled follow-up study. Mount Sinai Journal of Medicine 1972;39:251-7.

\section{Fink 1978 \{published data only\}}

* Fink EB, Longbaugh R, Stout R. The paradoxical underutilization of partial hospitalization. American Journal of Psychiatry 1978;135:713-6.

\section{Glick 1974 \{published data only\}}

Glick ID, Hargreaves WA, Drues JA, Showstack JA, Katzow JJ. Short versus long hospitalization: a prospective controlled study. VII. Two-year follow-up results for non-schizophrenics. Archives of General Psychiatry 1977;34:314-7.

Glick ID, Hargreaves WA, Drues JMA, Showstack JA. Short versus long hospitalization: a controlled study. III. Inpatient results for nonschizophrenics. Archives of General Psychiatry 1976;33:78-83.

Glick ID, Hargreaves WA, Drues JMA, Showstack JA. Short versus long hospitalization: a prospective controlled study. IV. Oneyear follow-up results for schizophrenic patients. American Journal of Psychiatry 1976;133:509-14.

Glick ID, Hargreaves WA, Drues JMA, Showstack JA. Short versus long hospitalization: a prospective controlled study. V. Oneyear follow up for non-schizophrenics. American Journal of Psychiatry 1976;133:515-7.

* Glick ID, Hargreaves WA, Goldfield MD. Short vs long hospitalization. A prospective controlled study. I. The preliminary results of a one-year follow-up for schizophrenics. Archives of General Psychiatry 1974;30:363-9.

Glick ID, Hargreaves WA, Raskin M, Kutner SJ. Short versus long hospitalization: a prospective controlled study. II. Results for schizophrenic inpatients. American Journal of Psychiatry 1975;132(4):385-90.

Hargreaves WA, Glick ID, Drues J, Showstack JA, Feigenbaum E. Short versus long hospitalization: a prospective controlled study. VI. Two-year follow-up results for schizophrenics. Archives of General Psychiatry 1977;34:305-11.

Grad 1968 \{published data only\}

${ }^{\star}$ Grad J, Sainsbury P. The effects that patients have on their families in a community care and a control psychiatric service - a two year follow-up. British Journal of Psychiatry 1968;114:265-78

\section{Gudeman 1983 \{published data only\}}

* Gudeman JE, Shore MF, Dickey B. Day hospitalization instead of inpatient care for psychiatric patients. New England Journal of Medicine 1983;308:749-53.

Guidry 1979 \{published data only\}

* Guidry LS, Winstead DK, Levine M, Eicke FJ. Evaluation of treatment center effectiveness. Journal of Clinical Psychiatry 1979;40:221-4

\section{Guillette 1978 \{published data only\}}

* Guillette W, Crowley B, Savitz S, Goldberg FD. Day hospitalization as a cost-effective alternative to inpatient care: a pilot study. Hospital \& Community Psychiatry 1978;29:525-7.

\section{Guy 1969 \{published data only\}}

Guy W, Gross M, Hogarty GE, Dennis H. A controlled evaluation of day hospital effectiveness. Archives of General Psychiatry 1969;20:329-38.

Hogarty GE, Dennis H, Guy W, Gross GM. Who goes there? A critical evaluation of admissions to a psychiatric day hospital. American Journal of Psychiatry 1968;124:934-44.

Hogarty GE, Guy W, Gross M, Gross G. An evaluation of community-based mental health programs: long-range effects. Medical Care 1969;7(4):271-80.

\section{Herz 1971 \{published data only\}}

* Herz MI, Endicott J, Spitzer RL, Mesnikoff A. Day versus inpatient hospitalization: a controlled study. American Journal of Psychiatry 1971;10:1371-82.

\section{Herz 1975 \{published data only\}}

Herz MI, Endicott J, Gibbon M. Brief hospitalization: two-year follow-up. Archives of General Psychiatry 1979;36(6):701-5.

* Herz MI, Endicott J, Spitzer RL. Brief hospitalization of patients with families: initial results. American Journal of Psychiatry 1975;132:413-8.

Herz MI, Endicott J, Spitzer RL. Brief hospitalization: a two-year follow-up. American Journal of Psychiatry 1977;134(5):502-7.

Herz MI, Endicott J, Spitzer RL. Brief versus standard hospitalization: the families. American Journal of Psychiatry. 1976;133(7):795-801. 
Hirsch1979 \{published data only\}

* Hirsch SR, Platt S, Knights A, Weyman A. Shortening hospital stay for psychiatric care: effect on patients and their families. British Medical Journal 1979;1:442-6.

\section{Hogg 1990 \{published data only\}}

* Hogg LI, Brooks N. New chronic schizophrenic patients: a comparison of daypatients and inpatients. Acta Psychiatrica Scandinavica 1990;81:271-6.

Inch1997 \{published data only\}

* Inch R, Crossley M, Keegan D, Thorarinson D. Use of the Brief Psychiatric Rating Scale to measure success in a psychosocial day program. Psychiatric Services 1997;48(9):1195-7.

\section{Jarema 1997 \{published data only\}}

* Jarema M, Bury L, Konieczynska Z, Zaborowski B, Cikowska G, Kunicka A, Bartoszewicz J, Muraszkiewicz L. Comparison of quality of life of schizophrenic patients in different forms of psychiatric care. Psychiatria Polska 1997;31(5):585-94.

Kandel 1981 \{published data only\}

* Kandel A, Langrod J, Ruiz P. Changes in future time perception of day hospital psychiatric patients in response to small group treatment approaches. Journal of Clinical Psychology 1981;37(4):769-81.

\section{Kecmanovic 1985 \{published data only\}}

* Kecmanovic D. Post release adjustment of day and inpatients. International Journal of Social Psychiatry 1985;31:74-9.

Klyczek 1986 \{published data only\}

* Klyczek JP, Mann WC. Therapeutic modality comparisons in day treatment. American Journal of Occupational Therapy 1986;40(9):606-11.

\section{Konieczynska 1997 \{published data only\}}

Konieczynska Z, Pietrzykowska B, Zaborowski B. Family burden of patients receiving inpatient treatment or alternative forms of psychiatric care. Psychiatria Polska 1997;31(5):625-35.

* Konieczynska Z, Pietrzykowska B, Zaborowski B. Follow-up studies of psychotic patients receiving inpatient treatment or alternative forms of psychiatric care. Psychiatria Polska 1997;31(5):615-24.

Kris 1965 \{published data only\}

* Kris EB. Day hospitals. Current Therapeutic Research 1965;7:320-3.

Kuldau 1977 \{published data only\}

* Kuldau JM, Stanley J, Dirks JD. Controlled evaluation of a hospital-originated community transitional system. Archives of General Psychiatry 1977;34:1331-40.

\section{Levenson 1977 \{published data only\}}

* Levenson AJ, Lord CJ, Sermas CE, Thornby JI, Sullender W, Comstock BS. Acute schizophrenia: an efficacious outpatient treatment approach as an alternative to full-time hospitalization. Diseases of the Nervous System 1977;38:242-5.

\section{Liang 1997 \{published data only\}}

* Liang Y, Chiang S, Lee T, Wu M, Yan H, Tsui H. A study of the objective life quality among chronic mentally ill patients. Nursing Research 1997;5(3):212-22.

Lystad 1958 \{published data only\}

* Lystad MH. Day hospital care and changing family attitudes toward the mentally ill. Journal of Nervous and Mental Disease 1958;127:145-52.

Mathai 1985 \{published data only\}

* Mathai PJ, Gopinath PS. Deficits of chronic schizophrenia in relation to long-term hospitalisation. British Journal of Psychiatry 1985;148:509-16.

McDonnell 1977 \{published data only\} McDonnell D. An evaluation of day centre care. International Journal of Social Psychiatry 1977;23(2):110-9.

Michaux 1969 \{published data only\}

Michaux MH, Chelst MR, Foster SA, Pruim RJ. Day and fulltime psychiatric treatment: a controlled comparison. Current Therapeutic Research 1972;14:279-92.

Michaux MH, Chelst MR, Foster SA, Pruim RJ, Dasinger EM. Postrelease adjustment of day and full-time psychiatric patients. Archives of General Psychiatry 1973;29(5):647-51.

* Michaux MH, Garmize K, Rossi JA, Schoolman LR, Gross GM. A controlled comparison of psychiatric day center treatment with full time hospitalization. Current Therapeutic Research 1969;11(4):190-204.

Milne 1984 \{published data only\}

* Milne D. A comparative evaluation of two psychiatric day hospitals. British Journal of Psychiatry 1984;145:533-7.

Newton 1983 \{published data only\}

Newton PA. An evaluation of the cost effectiveness of day hospitalization for black male schizophrenics. Journal of the National Medical Association 1983;75(3):273-85.

Niskanen 1974 \{published data only\}

* Niskanen P. Treatment results achieved in psychiatric day care: a follow-up of 100 patients. Acta Psychiatrica Scandinavica 1974;50:401-9.

\section{O'Shea 1998 \{published data only\}}

* O'Shea E, Hughes J, Fitzpatrick L, Dunne E, O'Sullivan M, Cole M. An economic evaluation of inpatient treatment versus day hospital care for psychiatric patients. Irish Journal of Psychological Medicine 1998;15(4):127-30.

Odenheimer 1965 \{published data only\}

* Odenheimer JF. Day hospital as an alternative to the psychiatric ward. Attitudes and responses of relatives. Archives of General Psychiatry 1965;13:46-53.

Oka 1999 \{published data only\}

* Oka K, Maeda M, Hirano T, Funahashi T, Yamada S. Multicenter study on the effects of day care therapy on schizophrenia: a 
comparison of day care patients with outpatients. Psychiatry \& Clinical Neurosciences 1999;53(4):505-10.

\section{Pang 1985 \{published data only\}}

Pang J. Partial hospitalization: an alternative to inpatient care. Psychiatric Clinics of North America 1985;8:587-95.

\section{Penk 1978 \{published data only\}}

* Penk WE, Charles HL, Van Hoose TA. Comparative effectiveness of day hospital and inpatient psychiatric treatment. Journal of Consulting and Clinical Psychology 1978;1:94-101.

Penk WE, Charles HL, Van Hoose TA. Psychological test comparison of day hospital and inpatient treatment. Journal of Clinical Psychology 1979;35(4):837-9.

\section{Piersma 1997 \{published data only\}}

* Piersma HL, Boes JL. Comparison of psychiatric day hospital patient and inpatient scores on the MCMI-III. Journal of Clinical Psychology 1997;53(6):629-34.

\section{Piper 1993 \{published data only\}}

Piper WE, Joyce AS, Azim HFA, Rosie JS. Patient characteristics and success in day treatment. Journal of Nervous and Mental Disease 1994;182:381-6.

Piper WE, Rosie JS, Azim HFA, Joyce AS. A randomized trial of psychiatric day treatment for patients with affective and personality disorders. Hospital and Community Psychiatry 1993;44:757-63.

Piper WE, Rosie JS, Joyce AS, Azim HFA. Time-limited day treatment for personality disorders: integration of research and practice in a group program. Washington D.C.: American Psychological Association, 1996.

\section{Platt 1980 \{published data only\}}

* Platt SD, Knights AC, Hirsch SR. Caution and conservatism in the use of a psychiatric day hospital: evidence from a research project that failed. Psychiatry Research 1980;3:123-32.

\section{Priebe 1999 \{published data only\}}

Priebe S, Gruyters T. A pilot trial of treatment changes according to schizophrenic patients' wishes. Journal of Nervous and Mental Disease 1999;187(7):441-3. [MEDLINE: 10426465]

\section{Priebe 2006 \{published data only\}}

Priebe S. Rct evaluating a new psychiatric day hospital for acute treatment: one year follow up. Current Controlled Trials 2004.

Priebe S, Jones G, McCabe R, Briscoe J, Wright D, Sleed M, Beecham J. Effectiveness and costs of acute day hospital treatment compared with conventional in-patient care: randomised controlled trial. British Journal of Psychiatry 2006;188:243-9.

\section{Priebe-MECCA-2002 \{unpublished data only\}}

Priebe S. Towards more effective Euorpean community care for patients with severe psychosis (MECCA). National Research Register 2003; Vol. 1.
Priebe S. Towards more effective European community care for patients with severe psychosis. Current Controlled Trials 2005.

Priebe S. Towards more effective community care for patients with severe psychosis - a randomised controlled trial on outcome management in six european countries. National Research Register 2001; Vol. 1.

Priebe S, McCabe R, Bullenkamp J, Hansson L, Lauber C, Martinez-Leal R, Rössler W, Salize H, Svensson B, TorresGonzales F, Van Den Brink R, Wiersma D, Wright DJ. Structured patient-clinician communication and 1-year outcome in community mental healthcare: cluster randomised controlled trial. The British Journal of Psychiatry 2007;191:420-6. [MEDLINE: 17978322]

* Priebe S, McCabe R, Bullenkamp J, Hansson L, Rossler W, Torres-Gonzales F, Wiersma D. The impact of routine outcome measurement on treatment processes in community mental health care: approach and methods of the MECCA study. Epidemiologia e Psichiatria Sociale 2002;11(3):198-205. [MEDLINE: 12451967]

\section{Prior 1998 \{published data only\}}

Prior S. Determining the effectiveness of a short-term anxiety management course. British Journal of Occupational Therapy 1998;61(5):207-13.

\section{Reynolds 2004 \{published data only\}}

Reynolds W, Lauder W, Sharkey S, Maciver S, Veitch T, Cameron D. The effects of a transitional discharge model for psychiatric patients. Journal of Psychiatric and Mental Health Nursing 2004;11(1):82-8. [MEDLINE: 14723643]

Russell 1996 \{published data only\}

* Russell V, Mai F, Busby K, Attwood D, Davis M, Brown M. Acute day hospitalization as an alternative to inpatient treatment. Canadian Journal of Psychiatry 1996;41(10):629-37.

Sandell 1993 \{published data only\}

* Sandell R, Alfredsson E, Berg M, Crafoord K. Clinical significance of outcome in long-term follow-up of borderline patients at a day hospital. Acta Psychiatrica Scandinavica 1993;87(6):405-13.

\section{Schene 1993 \{published data only\}}

* Schene AH, van Wijngaarden B, Poelijoe NW, Gersons BPR. The Utrecht comparative study on psychiatric day treatment and inpatient treatment. Acta Psychiatrica Scandinavica 1993;87:427-36.

\section{Skoda 1983 \{published data only\}}

Skoda C, Tomasek L, Bouchal M, Baudis P, Synkova J. A comparison of the effectiveness of three therapeutic preventive programs for neurotics. IV. Risk index for an unfavorable prognosis of the neurosis. Ceskoslovenska Psychiatrie 1983;79(2):131-7.

\section{Sledge 1996 \{published data only\}}

* Sledge WH, Tebes J, Rakfeldt J, Davidson L, Lyons L, Druss B. Day hospital/crisis respite care versus inpatient care. I. Clinical outcomes. American Journal of Psychiatry 1996;153:1065-73. 
Sledge WH, Tebes J, Wolff N, Helminiak TW. Day hospital/crisis respite care versus inpatient care. II. Service utilization and costs. American Journal of Psychiatry 1996;153:1074-83.

\section{Takano 1995 \{published data only\}}

Takano Y, Tsukahara T, Suzuki T, Hara T. The improvement of psychiatric symptoms of schizophrenic patients during day care treatment. Seishin Igaku 1995;37(4):369-76.

Tam 2000 \{published data only\}

* Tam SF, Ip YC, Chan CS. Self-concepts of hospitalized and day-care psychiatric patients. Journal of Social Psychology 2000;140(2):202-9.

\section{Tantam 1989 \{published data only\}}

* Tantam D, McGrath G. Psychiatric day hospitals - another route to institutionalization?. Social Psychiatry \& Psychiatric Epidemiology 1989;24:96-101.

Tsukahara 1998 \{published data only\}

Tsukahara T, Takano Y, Kato M, Kasahara T. The effect of day care treatment on duration of subsequent rehospitalization. Seishin Igaku 1998;40(10):1095-7.

\section{Tyrer 1979 \{published and unpublished data\}}

Tyrer P, Remington M, Alexander J. The outcome of neurotic disorders after out-patient and day hospital care. British Journal of Psychiatry 1987;151:57-62.

Tyrer PJ, Remington M. Controlled comparison of day-hospital and out-patient treatment for neurotic disorders. Lancet 1979;1:1014-6.

\section{Vaglum 1990 \{published data only\}}

* Vaglum P, Friis S, Irion T, Johns S, Karterud S, Larsen F, Vaglum $S$. Treatment response of severe and nonsevere personality disorders in a therapeutic community day unit. Journal of Personality Disorders 1990;4(2):161-72.

Vaitl 1989 \{published data only\}

* Vaitl P, Bender W, Hubmann W, Hummel C, Kroner A, Kroner M. Full inpatient versus partial inpatient psychiatric after-care - a comparative retrospective study. Psychiatrische Praxis 1989;16(6):214-7.

\section{Van Den Hout 1995 \{published data only\}}

* Van Den Hout JH, Arntz A, Kunkels FH. Efficacy of a self-control therapy program in a psychiatric day-treatment center. Acta Psychiatrica Scandinavica 1995;92(1):25-9.

\section{Vietze 1976 \{published data only\}}

Vietze G, Lange E, Ficker F, Ost H. Day-night therapy - a necessary step towards better care for mental patients. Psychiatrie, Neurologie und Medizinische Psychologie 1976;28(5):298-306.

\section{Washburn 1976 \{published data only\}}

Vannicelli M, Washburn S, Scheff BJ, Longabaugh R. Comparison of usual and experimental patients in a psychiatric day center. Journal of Consulting and Clinical Psychology 1978;46:87-93.
* Washburn S, Vannicelli M, Longabaugh R, Scheff BJ. A controlled comparison of psychiatric day treatment and inpatient hospitalization. Journal of Consulting and Clinical Psychology 1976;44:665-75.

Washburn SL, Vannicelli M, Scheff BJ. Irrational determinants of the place of psychiatric treatment. Hospital and Community Psychiatry 1976;27:179-82.

\section{Welburn 2000 \{published data only\}}

* Welburn K, Dagg, P, Coristine M, Pontefract A. Schematic change as a result of an intensive group-therapy day treatment program. Psychotherapy 2000;37(2):189-95.

\section{Wiersma 1994 \{published data only\}}

Kluiter H, Giel R, Nienhuis FJ, Ruphan M, Wiersma D. Predicting feasibility of day treatment for unselected patients referred for inpatient psychiatric treatment: results of a randomized trial. American Journal of Psychiatry 1992;149:1199-205.

* Nienhuis FJ, Giel R, Kluiter H, Ruphan M, Wiersma. Efficacy of psychiatric day treatment. Course and outcome of psychiatric disorders in a randomised trial. European Archives of Psychiatry \& Clinical Neuroscience 1994;244:73-80.

Wierma D, Kluiter H, Nienhuis F, Ruphan M, Giel R. Daytreatment with community care as an alternative to standard hospitalization: an experiment in the Netherlands. A preliminary communication. Department of Social Psychiatry, University of Groningen, 1989.

Wiersma D, Kluiter H, Nienhuis FJ, Ruphan M, Giel R. Costs and benefits of day treatment with community care for schizophrenic patients. Schizophrenia Bulletin 1991;3:411-9.

Wiersma D, Kluiter H, Nienhuis FJ, Ruphan M, Giel R. Costs and benefits of hospital and day treatment with community care of affective and schizophrenic disorders. British Journal of Psychiatry 1995;166:52-9.

\section{Wilberg 1998 \{published data only\}}

* Wilberg T, Friis S, Karterud S, Mehlum L, Urnes O, Vaglum P. Outpatient group psychotherapy: a valuable continuation treatment for patients with borderline personality disorder treated in a day hospital? A 3-year follow-up study. Nordic Journal of Psychiatry 1998;52(3):213-22.

\section{Zwerling 1964 \{published data only\}}

Wilder JF, Levin G, Zwerling I. A two-year follow-up evaluation of acute psychotic patients treated in a day hospital. American Journal of Psychiatry 1966;122:1095-101.

${ }^{*}$ Zwerling I, Wilder JF. An evaluation of the applicability of the day hospital in the treatment of acutely disturbed patients. Israel Annals of Psychiatry and Related Disciplines 1964;2:162-85.

\section{References to studies awaiting assessment}

Dal Santo 2004 \{published data only\}

Dal Santo B, Luoni A, Corbetta A, Scarone S. Uses and advantages of day hospital in psychiatric patients: 
an alternative way of care. Schizophrenia Research 2004;67(1):150-1.

\section{Additional references}

\section{Altman 1996}

Altman DG, Bland JM. Detecting skewness from summary information. BMJ 1996;313(7066):1200. [PUBMED: 8916759]

\section{Altman 2001}

Altman DG, Schulz KF, Moher D, Egger M, Davidoff F, Elbourne D, Gøtzsche PC, Lang T, CONSORT GROUP (Consolidated Standards of Reporting Trials). The revised CONSORT statement for reporting randomized trials: explanation and elaboration. Annals of internal medicine 2001;134(8):663-94. [PUBMED: 11304107]

\section{Anonymous 1987}

Anonymous. Psychiatric day hospitals for all?. Lancet $1987 ; 2: 1185$

\section{Bateman 2000}

Bateman AW, Fonagy P. Effectiveness of psychotherapeutic treatment of personality disorder. British Journal of Psychiatry 2000;177:138-43.

\section{Begg 1996}

Begg C, Cho M, Eastwood S, Horton R, Moher D, Olkin I, Pitkin R, Rennie D, Schulz KF, Simel D, Stroup DF. Improving the quality of reporting of randomized controlled trials. The CONSORT statement. JAMA : the journal of the American Medical Association 1996;276(8):637-9. [PUBMED: 8773637]

\section{Bland 1997}

Bland JM. Statistics notes. Trials randomised in clusters. BMJ 1997;315:600.

\section{Boissel 1999}

Boissel JP, Cucherat M, Li W, Chatellier G, Gueyffier F, Buyse M, Boutitie F, Nony P, Haugh M, Mignot G. The problem of therapeutic efficacy indices. 3. Comparison of the indices and their use [Apercu sur la problematique des indices d'efficacite therapeutique, 3: comparaison des indices et utilisation. Groupe d'Etude des Indices D'efficacite.]. Therapie 1999;54(4):405-11. [PUBMED: 10667106]

\section{Cameron 1947}

Cameron E. The day hospital. An experimental form of hospitalization for psychiatric patients. Modern Hospital 1947;69:60-3

\section{Casarino 1982}

Casarino JP, Wilner M, Maxey JT. American Association for Partial Hospitalization (AAPH) standards and guidelines for partial hospitalization. International Journal of Partial Hospitalization 1982;1(1):5-21.

\section{Deeks 2000}

Deeks J. Issues in the selection for meta-analyses of binary data. Proceedings of the 8th International Cochrane
Colloquium; 2000 Oct 25-28; Cape town. Cape Town: The Cochrane Collaboration, 2000.

\section{Derogatis 1977}

Derogatis LR. SCL-90-R: Administration, scoring and procedures manual, I, for the revised version. Baltimore: Clinical Psychometrics Research Unit, Johns Hopkins University, 1977.

\section{Divine 1992}

Divine GW, Brown JT, Frazier LM. The unit of analysis error in studies about physicians' patient care behavior. Journal of General Internal Medicine 1992;7(6):623-9.

\section{Donner 2002}

Donner A, Klar N. Issues in the meta-analysis of cluster randomized trials. Statistics in Medicine 2002;21:2971-80.

\section{Egger 1997}

Egger M, Davey-Smith G, Schneider M, Minder C. Bias in meta-analysis detected by a simple, graphical test. BMJ 1997;315:629-34.

\section{Elbourne 2002}

Elbourne D, Altman DG, Higgins JPT, Curtina F, Worthingtond HV, Vaile A. Meta-analyses involving crossover trials: methodological issues. International Journal of Epidemiology 2002;31(1):140-9.

\section{Endicott 1972}

Endicott J, Spitzer RL. What! another rating scale? The psychiatric evaluation form. Journal of Nervous and Mental Disease 1972;154:88-104.

\section{Endicott 1976}

Endicott J, Spitzer RL, Fleiss JL, Cohen J. The Global Assessment Scale: a procedure for measuring overall severity of psychiatric disturbance. Archives of General Psychiatry 1976;33:766-71.

\section{Greene 1981}

Greene LR, De La Cruz A. Psychiatric day treatment as alternative to and transition from full-time hospitalization. Community mental health journal 1981;17(3):191-202. [PUBMED: 6313285]

\section{Gulliford 1999}

Gulliford MC. Components of variance and intraclass correlations for the design of community-based surveys and intervention studies: data from the Health Survey for England 1994. American Journal of Epidemiology 1999;149:876-83.

\section{Higgins 2003}

Higgins JP, Thompson SG, Deeks JJ, Altman DG. Measuring inconsistency in meta-analyses. BMJ 2003;327:557-60.

\section{Higgins 2008}

Higgins JPT, Green S. Cochrane Handbook for systematic reviews of interventions 5.0.1[updated September 2008]. The Cochrane Collaboration. Chichester, UK: John Wiley and Sons, Ltd., 2008. 


\section{Hoge 1992}

Hoge MA, Davidson L, Leonard Hill W, Turner VE, Ameli R. The promise of partial hospitalization: a reassessment. Hospital and Community Psychiatry 1992;43:345-54.

\section{Kay 1986}

Kay SR, Opler LA, Fiszbein A. Positive and negative syndrome scale (PANSS) manual. North Tonawanda, NY: Multi-Health Systems, 1986

\section{Lamb 1967}

Lamb HR. Chronic psychiatric patients in the day hospital. Archives of General Psychiatry 1967;17:615-21.

\section{Leucht 2005}

Leucht S, Kane JM, Kissling W, Hamann J, Etschel E, Engel R. Clinical implications of Brief Psychiatric Rating Scale scores. British Journal of Psychiatry 2005;187:366-71. [PUBMED: 16199797]

\section{Leucht 2005a}

Leucht S, Kane JM, Kissling W, Hamann J, Etschel E, Engel RR. What does the PANSS mean?. Schizophrenia Research 2005;79(2-3):231-8. [PUBMED: 15982856]

\section{Linn 1969}

Linn MW, Sculthorpe WB, Evje M, Slater PH, Goodman SP. A social dysfunction rating scale. Journal of Psychiatric Research 1969;6:299-306.

\section{Malone 2007}

Malone D, Newron-Howes G, Simmonds S, Marriot S, Tyrer P. Community mental health teams (CMHTs) for people with severe mental illnesses and disordered personality. Cochrane Database of Systematic Reviews 2007, Issue 3. [DOI: 10.1002/14651858.CD000270.pub2]

\section{Marshall 2000}

Marshall M, Lockwood A, Adams C, Bradley C, Joy C, Fenton M. Unpublished rating scales - a major source of bias in randomised controlled trials of treatments for schizophrenia?. British Journal of Psychiatry 2000;176:249-52.

\section{Moscowitz 1980}

Moscowitz IS. The effectiveness of day hospital treatment: a review. Journal of Community Psychology 1980;8:155-64.

\section{Murray 1996}

Murray CL, Lopez AD. The global burden of disease. Cambridge: Harvard University Press, 1996.

\section{Overall 1962}

Overall JE, Gorham DR. The Brief Psychiatric Rating Scale. Psychological Reports 1962;10:799-812.

\section{Parker 1990}

Parker S, Knoll JL 3rd. Partial hospitalization: an update. The American Journal of Psychiatry 1990;147(2):156-60. [PUBMED: 2301652]

\section{Pryce 1982}

Pryce IG. An expanding "stage army" of long-stay psychiatric day-patients. British Journal of Psychiatry 1982;141:595-601.

\section{Roen 1966}

Roen SR, Ottenstein D, Cooper s, Burnes A. Community adaption as an evaluative concept in community mental health. Archives of General Psychiatry 1966;15:36-44.

\section{Rosie 1987}

Rosie JS. Partial hospitalization: a review of recent literature. Hospital and Community Psychiatry 1987;38:1291-9.

\section{Schene 1986}

Schene AH, Gersons BPR. Effectiveness and application of partial hospitalization. Acta Psychiatrica Scandinavica 1986;74:335-40.

\section{Schene 1988}

Schene AH, Van Lieshout PAH, Mastboom JCM. Different types of partial hospitalization programs: results of a nationwide survey in the Netherlands. Acta Psychiatrica Scandinavica 1988;78:515-22.

\section{Schulz 1995}

Schulz KF, Chalmers I, Hayes RJ, Altman DG. Empirical evidence of bias: dimensions of methodological quality associated with estimates of treatment effects in controlled trials. JAMA 1995;273:408-12.

\section{Ukoumunne 1999}

Ukoumunne OC, Gulliford MC, Chinn S, Sterne JAC, Burney PGJ. Methods for evaluating area-wide and organisation-based intervention in health and health care: a systematic review. Health Technology Assessment 1999;3(5):1-75.

\section{Warner 1995}

Warner R, De Girolamo G. Schizophrenia. Epidemiology of mental disorders and psychosocial problems. World Health Organization. Geneva, 1995.

\section{Weissman 1981}

Weismann MM, Sholomskas D, John K. The assessment of social adjustment: an update. Archives of General Psychiatry 1981;38:1250-8.

\section{WHO 2001}

World Health Organization. Mental health: New understanding, new hope. The world health report 20012001.

\section{Wilkinson 1984}

Wilkinson G. Day care for patients with psychiatric disorders. British Medical Journal 1984; Vol. 288, issue 6432:1710-2. [PUBMED: 6428508]

\section{Xia 2007}

Xia J, Adams CE, Bhagat N, Bhagat V, Bhoopathi P, El-Sayeh H, Pinfold V, Takriti Y. The Leeds Outcomes Stakeholders Survey (LOSS) Study. Proceedings of the 15th Cochrane Colloquium; 2007 Oct 23-27; Sao Paulo. The Cochrane Collaboration, 2007. 


\section{References to other published versions of this review \\ Marshall 2001}

Marshall M, Crowther R, Almaraz-Serrano AM, Tyrer P. Day hospital versus out-patient care for psychiatric disorders.
Cochrane Database of Systematic Reviews 2001, Issue 3. [DOI: 10.1002/14651858.CD003240]

* Indicates the major publication for the study

\section{CHARACTERISTICS OF STUDIES}

Characteristics of included studies [ordered by study ID]

\section{Glick 1986}

\begin{tabular}{|c|c|}
\hline Methods & $\begin{array}{l}\text { Allocation: random - no further details. } \\
\text { Blindness: unclear if evaluator was independent of treating clinician or blind to group allocation and if } \\
\text { statistical analysis performed blind. } \\
\text { Duration: } 12 \text { months. } \\
\text { Setting: day hospital attached to New York Hospital. }\end{array}$ \\
\hline Participants & $\begin{array}{l}\text { Diagnosis: schizophrenia } n=37 \text {, major affective disorder } n=42 . \\
\text { N=79 (sub-group of } 37 \text { reported in this review). } \\
\text { Age: } ~ 30 \text { years old (schizophrenia sub-group). } \\
\text { Sex: } 22 \mathrm{M}, 15 \mathrm{~F} \text { (schizophrenia sub-group). } \\
\text { History: referred from inpatient wards of New York Hospital, number of previous admissions not report- } \\
\text { ed, had schizophrenia/major affective disorder; were discharged from IP unit; } 18 \text { to } 60 ; \text { no more than } \\
\text { two previous admissions; inadequate family support; residual psychotic symptoms; need for ongoing } \\
\text { treatment. }\end{array}$ \\
\hline
\end{tabular}

Interventions
ive \& group therapy; medication; care management; recreation \& dance therapy; discharge planning.
$\mathrm{N}=19$.
2. OP follow-up: 6 to 12 weeks in outpatient group therapy (90 mins/wk); medication management; 24
hr crisis intervention. $\mathrm{N}=18$.

$\begin{array}{ll}\text { Outcomes } & \text { Service use: hospital admission. } \\ \text { Global state: number lost to follow up, GAS } \\ \text { Social functioning: SAS. } \\ \text { Mental state: Psychiatric Evaluation Form. } \\ \text { Unable to use - } \\ \text { Service use: rate of admission (not reported by sub-groups). } \\ \text { Social functioning: Role performance Treatment Scale (unpublished scale). } \\ \text { Medication compliance (unpublished scale). }\end{array}$

\section{Notes}

\section{Risk of bias}

\begin{tabular}{lll}
\hline Bias & Authors' judgement & Support for judgement \\
\hline $\begin{array}{l}\text { Adequate sequence gener- } \\
\text { ation? }\end{array}$ & Unclear risk & "randomly assigned" - subcategorised by diagnosis, no further details. \\
\hline Allocation concealment? & Unclear risk & No details. \\
\hline $\begin{array}{l}\text { Blinding? } \\
\text { All outcomes }\end{array}$ & High risk & Not blinded by design. \\
\hline
\end{tabular}

Incomplete outcome data Unclear risk The reasons for leaving the study are not mentioned.
addressed?


Glick 1986 (Continued)

All outcomes

Free of selective report- Unclear risk Methods described consistent with outcomes reported, no protocol available.
ing?

Free of other bias? Unclear risk Authors did not declare sources of support and the interests in study.

Linn 1979

\begin{tabular}{|c|c|}
\hline Methods & $\begin{array}{l}\text { Allocation: randomised. } \\
\text { Blindness: evaluator was independent of DTC and blind to allocation. } \\
\text { Duration: } 24 \text { months. } \\
\text { Setting: } 10 \text { Veterans' Administration hospitals with associated Day Care centres. }\end{array}$ \\
\hline Participants & $\begin{array}{l}\text { Diagnosis: schizophrenia. } \\
\mathrm{N}=162 \text { ( } \mathrm{N} \text { assessed }=175) \text {. } \\
\text { Age: average } 37 \text { years old. } \\
\text { Sex: all male. } \\
\text { History: recently discharged from IP ( } 158 \text { days/year in hospital), referred for } \mathrm{DH} \text {, average number of ad- } \\
\text { missions in year preceding trial - 4.4, receiving maintenance level of antipsychotic drugs, able to attend } \\
\text { DH. }\end{array}$ \\
\hline Interventions & $\begin{array}{l}\text { 1. VA day care centre: employed social workers \& physicians - aimed to enhance social functioning by } \\
\text { offering place to socialise and engage in productive activities, recreational activities, group therapy, } \\
\text { counselling, occupational therapy, medication follow up. } \mathrm{N}=80 \text {. } \\
\text { 2. OP drug management: same physicians as above - no other aftercare offered. } \mathrm{N}=82 \text {. }\end{array}$ \\
\hline Outcomes & $\begin{array}{l}\text { Service use: admission to hospital. } \\
\text { Unable to use - } \\
\text { Service use: mean days in hospital (no SD) } \\
\text { Global state: leaving the study early (not reported by group - 15\% at } 24 \text { months). } \\
\text { Social functioning: SDRS (no SD). } \\
\text { Mental state: BPRS (no SD). } \\
\text { Cost of care (averages, no SD). } \\
\text { Attitudes (unpublished scale). }\end{array}$ \\
\hline
\end{tabular}

Notes

\section{Risk of bias}

\begin{tabular}{|c|c|c|}
\hline Bias & Authors' judgement & Support for judgement \\
\hline $\begin{array}{l}\text { Adequate sequence gener- } \\
\text { ation? }\end{array}$ & Unclear risk & Randomised - no further details. \\
\hline Allocation concealment? & Low risk & By means of sealed envelope corresponding to patient's number. \\
\hline $\begin{array}{l}\text { Blinding? } \\
\text { All outcomes }\end{array}$ & Low risk & Independent raters, authors affirm that outcome data blinded. \\
\hline $\begin{array}{l}\text { Incomplete outcome data } \\
\text { addressed? } \\
\text { All outcomes }\end{array}$ & Unclear risk & $\begin{array}{l}\text { Major reason for leaving the study was moving from area but not reported by } \\
\text { group of allocation. }\end{array}$ \\
\hline
\end{tabular}


Linn 1979 (Continued)

\begin{tabular}{lll}
$\begin{array}{l}\text { Free of selective report- } \\
\text { ing? }\end{array}$ & Unclear risk & Methods described consistent with outcomes reported, no protocol available. \\
\hline Free of other bias? & Unclear risk & $\begin{array}{l}\text { It was not reported whether blinding was successful. Authors did not declare } \\
\text { sources of support and interests in the study. }\end{array}$
\end{tabular}

\section{Meltzoff 1966}

$\begin{array}{ll}\text { Methods } & \text { Allocation: randomised. } \\ & \text { Blindness: independent of treating clinicians, initially blind to group allocation. Unclear if data analysis } \\ & \text { was carried out blind. } \\ & \text { Duration: } 18 \text { months. } \\ & \text { Setting: day care centre in New York. } \\ & \text { Diagnosis: } 91 \% \text { schizophrenia, } 1.5 \% \text { affective, } 6 \% \text { neurotic. } \\ \text { N=80. } & \text { Age: } \sim 41 \text { years. } \\ & \text { Sex: all male. } \\ & \text { History: veterans, with a service-connected neuropsychiatric disability, having spent time in hospital } \\ & \text { (average duration of admissions } 4.23 \text { yrs), not suicidal or violent. }\end{array}$

\begin{tabular}{l} 
Interventions $\begin{array}{l}\text { 1. Day care centre: individual \& group psychotherapy \& medication, patient/staff ratio not reported. } \\
\mathrm{N}=40 \text {. } \\
\text { 2. Standard outpatient care. } \mathrm{N}=40 .\end{array}$ \\
\hline
\end{tabular}

\begin{tabular}{ll}
\hline Outcomes & Service use: admission to hospital. \\
& Global state: number lost to follow up. \\
& Unable to use - \\
& Service use: days in hospital (no SD, no ITT). \\
& Social functioning (Outpatient Adjustment Rating Scales, unpublished). \\
\hline
\end{tabular}

\section{Notes}

\section{Risk of bias}

\begin{tabular}{lll}
\hline Bias & Authors' judgement & Support for judgement \\
\hline $\begin{array}{l}\text { Adequate sequence gener- } \\
\text { ation? }\end{array}$ & Low risk & Randomised - 80 cards shuffled by use of table of random numbers. \\
\hline Allocation concealment? & Unclear risk & $\begin{array}{l}\text { Deck of cards kept in custody of research personnel, top card drown only when } \\
\text { name of patient brought in. Researchers noted 42\% married (outpatient) ver- } \\
\text { sus } 27 \% \text { married (day treatment) - but no information on how many variables } \\
\text { they compared. }\end{array}$ \\
\hline $\begin{array}{l}\text { Blinding? } \\
\text { All outcomes }\end{array}$ & Unclear risk & $\begin{array}{l}\text { Research personnel had no dealing with patients, but patients were ques- } \\
\text { tioned about their day by their assessor. }\end{array}$ \\
\hline $\begin{array}{l}\text { Incomplete outcome data } \\
\text { addressed? } \\
\text { All outcomes }\end{array}$ & Unclear risk & Missing data on 29 interviews reported but not explained. \\
\hline $\begin{array}{l}\text { Free of selective report- } \\
\text { ing? }\end{array}$ & Unclear risk & Methods described consistent with outcomes reported, no protocol available. \\
\hline
\end{tabular}


Meltzoff 1966 (Continued)

Free of other bias? Unclear risk It was not reported whether blinding was successful. Authors did not declare sources of support and interests in the study. 11 subjects were removed from the study after randomisation - the reasons stated as poor attendance or failure to attend.

Weldon 1979

\begin{tabular}{ll} 
Methods & Allocation: random - no further details. \\
& Blindness: unclear if independent or blind to group allocation. \\
& Duration: three months. \\
& Setting: day hospital in New York. \\
\hline Participants & Diagnosis: schizophrenia. \\
$\mathrm{N}=30$ (N assessed not known). \\
Age: 37 years. \\
Sex: 9 M, 21 F. \\
History: recently discharged, not suicidal, violent or abusing drugs, 19 persons had two or more previ- \\
ous admissions.
\end{tabular}

1. Day hospital treatment: intensive 5 days/week group therapy, recreational/prevocational activi-
ties/therapy, patient/staff ratio $-2.5 . \mathrm{N}=15$.

2. Psychotherapy oriented OP care: including medication clinic. $\mathrm{N}=15$.

\begin{tabular}{|c|c|c|}
\hline Outcomes & \multicolumn{2}{|c|}{$\begin{array}{l}\text { Service use: admission to hospital. } \\
\text { Global state: number lost to follow up. } \\
\text { Social functioning: CAS, employment. } \\
\text { Mental state: POMS, SCL-90. }\end{array}$} \\
\hline \multicolumn{3}{|l|}{ Notes } \\
\hline \multicolumn{3}{|l|}{ Risk of bias } \\
\hline Bias & Authors' judgement & Support for judgement \\
\hline $\begin{array}{l}\text { Adequate sequence gener- } \\
\text { ation? }\end{array}$ & Unclear risk & "Randomly assigned" (no details). \\
\hline Allocation concealment? & Unclear risk & No details on concealment. \\
\hline $\begin{array}{l}\text { Blinding? } \\
\text { All outcomes }\end{array}$ & High risk & Not blinded by design. \\
\hline $\begin{array}{l}\text { Incomplete outcome data } \\
\text { addressed? } \\
\text { All outcomes }\end{array}$ & Low risk & No loss to follow up. \\
\hline $\begin{array}{l}\text { Free of selective report- } \\
\text { ing? }\end{array}$ & Unclear risk & Methods described consistent with outcomes reported, no protocol available. \\
\hline Free of other bias? & Unclear risk & Due to small sample size and short duration of the study. \\
\hline
\end{tabular}

Abbreviations:

Anx - anxiety.

Behav - behavioural.

BPRS - Brief Psychiatric Rating Scale. 
CAS - Community Adaptation Schedule.

Dep - depression.

$\mathrm{DH}$ - day hospital.

IP - Inpatient care.

IPD - individual patient data were used to calculate this outcome.

ITT - intention to treat analysis.

Meds - medication.

Mod - moderate.

OP - outpatient.

PD - personality disorder.

POMS - Profile of Mood States.

PSE - Present State Examination.

SCID - Structured Clinical Interview for DSM IIIR.

SCL - Symptom Check-List.

SCZ - schizophrenia.

SD - standard deviation.

SDRS - Social Dysfunction Rating Scale.

VA - Veterans' Administration.

Characteristics of excluded studies [ordered by study ID]

\begin{tabular}{|c|c|}
\hline Study & Reason for exclusion \\
\hline Austin 1976 & $\begin{array}{l}\text { Allocation: not randomised, survey comparing randomly selected subjects from two different day } \\
\text { hospitals. }\end{array}$ \\
\hline Azim 1978 & $\begin{array}{l}\text { Allocation: not randomised, quasi-experimental design comparing outcome for patients in a day } \\
\text { treatment program for non-psychotic patients, with non-patient controls. }\end{array}$ \\
\hline Barkley 1989 & Allocation: not randomised, retrospective study of admission rates at three day care centres. \\
\hline Basker 1986 & Allocation: not randomised, before and after design. \\
\hline Bateman 1999 & $\begin{array}{l}\text { Allocation: randomised. } \\
\text { Participants: people with borderline personality disorder, not people with schizophrenia. }\end{array}$ \\
\hline Beigel 1970 & Allocation: not randomised, survey. \\
\hline Bertrand 1973 & Allocation: not randomised. \\
\hline Boath 1999 & $\begin{array}{l}\text { Allocation: not randomised, quasi-experimental design. } \\
\text { Participants: people in a day treatment program for post-natal depression, not people with schizo- } \\
\text { phrenia. }\end{array}$ \\
\hline Bowman 1983 & Allocation: not randomised, survey. \\
\hline Bradshaw 2000 & $\begin{array}{l}\text { Allocation: randomised. } \\
\text { Participants: people with schizophrenia who were long-term attenders at a day care centre. } \\
\text { Intervention: day care plus cognitive behavioural therapy versus day care alone, not day care ver- } \\
\text { sus outpatient care. }\end{array}$ \\
\hline Brook 1973 & Allocation: not randomised, survey. \\
\hline Carey 1990 & $\begin{array}{l}\text { Allocation: randomised. } \\
\text { Participants: attenders at a day care centre who also abused substances. } \\
\text { Intervention: problem-solving training plus day care versus day care alone, not day hospital versus } \\
\text { outpatient care. }\end{array}$ \\
\hline
\end{tabular}




\begin{tabular}{ll}
\hline Study & Reason for exclusion \\
\hline Case 1991 & Allocation: not randomised, retrospective study. \\
\hline Comstock 1985 & Allocation: not randomised, retrospective multivariate analysis. \\
\hline Creed 1989 & Allocation: not randomised, quasi-experimental design - consecutive admissions. \\
\hline Creed 1990 & $\begin{array}{l}\text { Allocation: randomised. } \\
\text { Participants: people with acute psychiatric disorders requiring admission to hospital. } \\
\text { Intervention: acute day hospital versus inpatient care, not day hospital versus outpatient care. }\end{array}$ \\
\hline
\end{tabular}

\section{Creed 1991}

Allocation: randomised, by sealed envelope - however, trialists judged that randomisation procedure had been compromised.

Participants: acute psychiatric patients about to be admitted to inpatient care.

Intervention: acute day hospital versus inpatient care, not day hospital versus outpatient care.

Creed 1997
$\begin{aligned} & \text { Allocation: randomised. } \\ & \text { Participants: people with acute psychiatric disorders requiring admission to hospital. } \\ & \text { Intervention: acute day hospital versus inpatient care, not day hospital versus outpatient care. }\end{aligned}$

\begin{tabular}{ll}
\hline Dick 1985 & Allocation: randomised. \\
& Participants: people with acute psychiatric disorders requiring admission to hospital. \\
& Intervention: acute day hospital versus inpatient care, not day hospital versus outpatient care.
\end{tabular}

\begin{tabular}{ll}
\hline Dick 1991 & $\begin{array}{l}\text { Allocation: randomised. } \\
\text { Participants: people with persistent anxiety and depression, not schizophrenia. }\end{array}$ \\
\hline Drake 1994 & Allocation: not randomised, quasi-experimental design. \\
\hline Ettlinger 1972 & Allocation: not randomised, retrospective case-control study. \\
\hline Glick 1974 & Allocation: not randomised, quasi-experimental study. \\
\hline Grad 1968 & $\begin{array}{l}\text { Allocation: randomised. } \\
\text { Participants: people requiring hospital inpatient care. } \\
\text { Intervention: short versus long hospital admission, not day hospital versus outpatient care. }\end{array}$ \\
\hline Gudeman 1983 & Allocation: not randomised, quasi-experimental design. \\
\hline Guidry 1979 & Allocation: not randomised, before and after design. \\
\hline Guillette 1978 & Allocation: not randomised, before and after design. \\
\hline Guy 1969 & Allocation: not randomised, cross-sectional study. \\
\hline & $\begin{array}{l}\text { Allocation: randomised. } \\
\text { Participants: people with schizophrenia, depression, neuroses in need of inpatient care did not } \\
\text { meet criteria of 'not acutely ill'. }\end{array}$ \\
\hline
\end{tabular}

Herz 1971

Allocation: randomised (random number table).

Participants: people with acute psychiatric disorders admitted to inpatient care.

Intervention: acute day hospital care versus admission, not day hospital versus outpatient care.

Herz 1975

Allocation: randomised.

Participants: people with acute psychiatric disorders about to be admitted to inpatient care. Interventions: routine inpatient care versus brief inpatient care plus day care, not day hospital versus outpatient care. 


\section{\begin{tabular}{ll} 
Study Reason for exclusion \\
\hline
\end{tabular}}

Hirsch1979

Allocation: random allocation.

Participants: people with acute psychiatric disorders about to be admitted to inpatient care. Intervention: brief inpatient care with some transitional day hospital care versus routine inpatient care, not day hospital versus outpatient care.

\begin{tabular}{ll}
\hline Hogg 1990 & Allocation: not randomised, survey. \\
\hline Inch1997 & Allocation: not randomised, prospective study. \\
\hline Jarema 1997 & Allocation: not randomised, survey. \\
\hline Kandel 1981 & $\begin{array}{l}\text { Allocation: randomised. } \\
\text { Participants: adult general psychiatry patients attending a day treatment program. } \\
\text { Intervention: day treatment plus a small group intervention versus day treatment alone, not day } \\
\text { hospital versus outpatient care. }\end{array}$
\end{tabular}

\begin{tabular}{ll}
\hline Kecmanovic 1985 & Allocation: not randomised, cross-sectional case-control study. \\
\hline Klyczek 1986 & Allocation: not randomised, quasi-experimental design. \\
\hline Konieczynska 1997 & Allocation: not randomised, follow up study. \\
\hline Kris 1965 & $\begin{array}{l}\text { Allocation: randomised. } \\
\text { Participants: people requiring admission for acute relapse of schizophrenia. } \\
\text { Intervention: acute day hospital versus inpatient care, not day hospital versus outpatient care. }\end{array}$ \\
\hline Kuldau 1977 & $\begin{array}{l}\text { Allocation: randomised. } \\
\text { Participants: inpatients about to be discharged. } \\
\text { Intervention: rapid discharge from inpatient care versus community transitional system (which in- } \\
\text { volves gradual discharge from hospital), not day hospital versus outpatient care. }\end{array}$
\end{tabular}

\begin{tabular}{ll}
\hline Levenson 1977 & Allocation: randomised by table random numbers. \\
& Participants: people with acute relapse of schizophrenia. \\
& Intervention: treatment in an outpatient clinic versus hospital admission, not day hospital versus \\
& outpatient care.
\end{tabular}

\begin{tabular}{ll}
\hline Liang 1997 & Allocation: not randomised, survey. \\
\hline Lystad 1958 & Allocation: not randomised, quasi-experimental design. \\
\hline Mathai 1985 & Allocation: not randomised, survey. \\
\hline McDonnell 1977 & Allocation: not randomised, survey. \\
\hline Michaux 1969 & Allocation: not randomised, quasi-experimental design. \\
\hline Milne 1984 & Allocation: not randomised, quasi-experimental study. \\
\hline Newton 1983 & Allocation: not randomised. \\
\hline Niskanen 1974 & Allocation: not randomised, before and after design. \\
\hline O'Shea 1998 & Allocation: not randomised, retrospective cost-effectiveness analysis. \\
\hline Odenheimer 1965 & Allocation: not randomised, survey. \\
\hline
\end{tabular}




\begin{tabular}{ll}
\hline Study & Reason for exclusion \\
\hline Oka 1999 & Allocation: not randomised, quasi-experimental design. \\
\hline Pang 1985 & $\begin{array}{l}\text { Allocation: unclear. } \\
\text { Participants: unclear. } \\
\text { Intervention: partial hospitalisation versus inpatient care, not day hospital versus outpatient care. }\end{array}$ \\
\hline Penk 1978 & Allocation: not randomised, quasi-experimental study. \\
\hline Piersma 1997 & Allocation: not randomised, quasi-experimental study. \\
\hline Piper 1993 & $\begin{array}{l}\text { Allocation: randomised. } \\
\text { Participants: people with affective and personality disorders, not schizophrenia. }\end{array}$ \\
\hline Platt 1980 & $\begin{array}{l}\text { Allocation: randomised. } \\
\text { Participants: people with acute psychiatric disorders. } \\
\text { Intervention: admission to day hospital versus inpatient care, not day hospital versus outpatient } \\
\text { care. }\end{array}$ \\
\hline Priebe 1999 & $\begin{array}{l}\text { Allocation: randomised. } \\
\text { Participants: people with severe psychosis. } \\
\text { Intervention: treatment changes according to patient wishes versus standard care, not day hospital } \\
\text { versus outpatient care. }\end{array}$ \\
\hline
\end{tabular}

\begin{tabular}{ll}
\hline Priebe 2006 & $\begin{array}{l}\text { Allocation: randomised. } \\
\text { Participants: people with severe psychosis. } \\
\text { Intervention: day hospital versus inpatient care, not day hospital versus outpatient care. }\end{array}$ \\
\hline Priebe-MECCA-2002 & $\begin{array}{l}\text { Allocation: randomised. } \\
\text { Participants: people with severe psychosis. } \\
\text { Intervention: package of care within which outcomes were fed back to patients versus standard } \\
\text { care, not day hospital versus outpatient care. }\end{array}$
\end{tabular}

\begin{tabular}{ll}
\hline Prior 1998 & Allocation: not randomised. \\
& Participants: people with various diagnosis with anxiety as a main problem, not people with schiz- \\
& ophrenia.
\end{tabular}

\begin{tabular}{ll}
\hline Reynolds 2004 & Allocation: randomised. \\
& Participants: people with bipolar disorder, schizophrenia, depression. \\
& Intervention: transitional discharge model versus referral to locality-based community psychiatric \\
nurses, not day hospital versus outpatient care.
\end{tabular}

\begin{tabular}{ll}
\hline Russell 1996 & Allocation: not randomised, retrospective study. \\
\hline Sandell 1993 & Allocation: not randomised, cohort study. \\
\hline Schene 1993 & $\begin{array}{l}\text { Allocation: randomised. } \\
\text { Participants: people with acute psychiatric disorders requiring admission to hospital. } \\
\text { Intervention: acute day hospital versus inpatient, not day hospital versus outpatient care. }\end{array}$ \\
\hline Skoda 1983 & $\begin{array}{l}\text { Allocation: randomised. } \\
\text { Participants: people with neurosis, not schizophrenia. }\end{array}$ \\
\hline Sledge 1996 & $\begin{array}{l}\text { Allocation: randomised. } \\
\text { Participants: people with acute psychiatric disorders requiring admission to hospital. } \\
\text { Intervention: acute day hospital with crisis residence versus inpatient care, not day hospital versus } \\
\text { outpatient care. }\end{array}$ \\
\hline
\end{tabular}




\begin{tabular}{|c|c|}
\hline Study & Reason for exclusion \\
\hline Takano 1995 & Allocation: not randomised. \\
\hline Tam 2000 & Allocation: not randomised, survey. \\
\hline Tantam 1989 & Allocation: not randomised, quasi-experimental study (using matched controls). \\
\hline Tsukahara 1998 & Allocation: not randomised. \\
\hline Tyrer 1979 & $\begin{array}{l}\text { Allocation: randomised. } \\
\text { Participants: people with neurotic disorders, not schizophrenia. }\end{array}$ \\
\hline Vaglum 1990 & Allocation: not randomised, follow up study. \\
\hline Vaitl 1989 & Allocation: not randomised, retrospective study. \\
\hline Van Den Hout 1995 & $\begin{array}{l}\text { Allocation: randomised. } \\
\text { Participants: depressed patients on a day treatment program. } \\
\text { Intervention: self-control therapy plus day care versus day care, not day hospital versus outpatient } \\
\text { care. }\end{array}$ \\
\hline Vietze 1976 & Allocation: not randomised. \\
\hline Washburn 1976 & $\begin{array}{l}\text { Allocation: randomised. } \\
\text { Participants: women receiving inpatient treatment. } \\
\text { Intervention: continuing inpatient admission versus discharge to day patient care, not day hospital } \\
\text { versus outpatient care. }\end{array}$ \\
\hline Welburn 2000 & Allocation: not randomised, quasi-experimental design. \\
\hline Wiersma 1994 & $\begin{array}{l}\text { Allocation: randomised. } \\
\text { Participants: people with acute psychiatric disorders requiring admission to hospital. } \\
\text { Intervention: acute day hospital versus inpatient care, not day hospital versus outpatient care. }\end{array}$ \\
\hline Wilberg 1998 & Allocation: not randomised, quasi-experimental study. \\
\hline Zwerling 1964 & $\begin{array}{l}\text { Allocation: randomised. } \\
\text { Participants: people with acute psychiatric disorders requiring admission to hospital. } \\
\text { Intervention: acute day hospital versus inpatient care, not day hospital versus outpatient care. }\end{array}$ \\
\hline
\end{tabular}

Characteristics of studies awaiting assessment [ordered by study ID]

\section{Dal Santo 2004}

\begin{tabular}{ll}
\hline Methods & Allocation: unclear. \\
\hline Participants & $\begin{array}{l}\text { Diagnosis: unclear - "psychiatric patients". } \\
\text { History: people being diverted from hospital admission. }\end{array}$ \\
\hline Interventions & Day hospital. \\
\hline Outcomes & Hospitalisation. \\
\hline Notes & Abstract only - more information requested June 2009. \\
\hline
\end{tabular}


DATA AND ANALYSES

Comparison 1. DAY HOSPITAL versus OUT-PATIENT CARE - NEAR OR ON DISCHARGE

\begin{tabular}{|c|c|c|c|c|}
\hline Outcome or subgroup title & $\begin{array}{l}\text { No. of } \\
\text { studies }\end{array}$ & $\begin{array}{l}\text { No. of } \\
\text { partici- } \\
\text { pants }\end{array}$ & Statistical method & Effect size \\
\hline $\begin{array}{l}1 \text { Deaths (all causes) - day treat- } \\
\text { ment centres }\end{array}$ & 1 & 30 & Risk Difference (M-H, Fixed, 95\% Cl) & $0.0[-0.12,0.12]$ \\
\hline 1.1 by 6 months & 1 & 30 & Risk Difference (M-H, Fixed, 95\% CI) & $0.0[-0.12,0.12]$ \\
\hline $\begin{array}{l}2 \text { Service use: Admitted to hos- } \\
\text { pital during study - day treat- } \\
\text { ment centres }\end{array}$ & 3 & & Risk Ratio (M-H, Random, 95\% Cl) & Subtotals only \\
\hline 2.1 by 6 months & 2 & 110 & Risk Ratio (M-H, Random, 95\% Cl) & $0.58[0.26,1.33]$ \\
\hline 2.2 by/at 12 months & 2 & 242 & Risk Ratio (M-H, Random, 95\% Cl) & $0.68[0.38,1.22]$ \\
\hline 2.3 beyond 12 months & 2 & 242 & Risk Ratio (M-H, Random, 95\% Cl) & $0.63[0.34,1.19]$ \\
\hline $\begin{array}{l}3 \text { Global state: } 1 \text {. Number lost to } \\
\text { follow up - day treatment cen- } \\
\text { tres / transitional day hospital }\end{array}$ & 3 & & Risk Ratio (M-H, Fixed, 95\% Cl) & Subtotals only \\
\hline 3.1 by 6 months & 3 & 147 & Risk Ratio (M-H, Fixed, 95\% Cl) & $0.97[0.48,1.95]$ \\
\hline 3.2 by/at 12 months & 2 & 117 & Risk Ratio (M-H, Fixed, 95\% Cl) & $0.97[0.48,1.95]$ \\
\hline $\begin{array}{l}4 \text { Global state: } 2 \text {. Average score } \\
\text { (GAS, high score = good) - transi- } \\
\text { tional day hospital }\end{array}$ & 1 & & Mean Difference (IV, Fixed, 95\% CI) & Subtotals only \\
\hline 4.1 by 6 months & 1 & 37 & Mean Difference (IV, Fixed, 95\% CI) & $-7.90[-15.68,-0.12]$ \\
\hline 4.2 by/at 12 months & 1 & 37 & Mean Difference (IV, Fixed, 95\% CI) & $-4.31[-15.24,6.62]$ \\
\hline $\begin{array}{l}5 \text { Social functioning: 1a. Aver- } \\
\text { age score (CAS, high score = } \\
\text { bad) - day treatment centres }\end{array}$ & 1 & & Mean Difference (IV, Fixed, 95\% CI) & Subtotals only \\
\hline 5.1 by 6 months & 1 & 30 & Mean Difference (IV, Fixed, 95\% CI) & $-0.03[-0.30,0.24]$ \\
\hline $\begin{array}{l}6 \text { Social functioning: } 1 \text { b. Aver- } \\
\text { age score (SAS, high score = } \\
\text { bad) - transitional day hospital }\end{array}$ & 1 & & Mean Difference (IV, Fixed, 95\% CI) & Subtotals only \\
\hline 6.1 by 6 months & 1 & 37 & Mean Difference (IV, Fixed, 95\% CI) & $0.36[-0.07,0.79]$ \\
\hline 6.2 by/at 12 months & 1 & 37 & Mean Difference (IV, Fixed, 95\% CI) & $0.17[-0.25,0.59]$ \\
\hline $\begin{array}{l}7 \text { Social functioning: } 2 \text {. Unem- } \\
\text { ployed - day treatment centres }\end{array}$ & 2 & & Risk Ratio (M-H, Random, 95\% Cl) & Subtotals only \\
\hline
\end{tabular}




\begin{tabular}{|c|c|c|c|c|}
\hline Outcome or subgroup title & $\begin{array}{l}\text { No. of } \\
\text { studies }\end{array}$ & $\begin{array}{l}\text { No. of } \\
\text { partici- } \\
\text { pants }\end{array}$ & Statistical method & Effect size \\
\hline 7.1 by 6 months & 1 & 30 & Risk Ratio (M-H, Random, 95\% Cl) & $0.04[0.00,0.62]$ \\
\hline 7.2 beyond 12 months & 1 & 80 & Risk Ratio (M-H, Random, 95\% Cl) & $0.86[0.69,1.06]$ \\
\hline $\begin{array}{l}8 \text { Mental state: } 1 \text { a. Average } \\
\text { score }(P E F, \text { high score = good) - } \\
\text { transitional day hospital }\end{array}$ & 1 & & Mean Difference (IV, Fixed, 95\% CI) & Subtotals only \\
\hline 8.1 by 6 months & 1 & 37 & Mean Difference (IV, Fixed, 95\% CI) & $0.52[-0.02,1.06]$ \\
\hline 8.2 by/at 12 months & 1 & 37 & Mean Difference (IV, Fixed, 95\% CI) & $0.15[-0.46,0.76]$ \\
\hline $\begin{array}{l}9 \text { Mental state: } 1 \mathrm{~b} \text {. Average } \\
\text { score (POMS, high score = bad) - } \\
\text { day treatment centres }\end{array}$ & 1 & & Mean Difference (IV, Fixed, 95\% CI) & Subtotals only \\
\hline 9.1 by 6 months & 1 & 30 & Mean Difference (IV, Fixed, 95\% CI) & $16.93[-20.49,54.35]$ \\
\hline $\begin{array}{l}10 \text { Mental state: } 1 \mathrm{c} \text {. Average } \\
\text { score }(\text { SCL90, high score = bad) - } \\
\text { day treatment centres }\end{array}$ & 1 & & Mean Difference (IV, Fixed, 95\% CI) & Subtotals only \\
\hline 10.1 by 6 months & 1 & 30 & Mean Difference (IV, Fixed, 95\% CI) & $0.31[-0.20,0.82]$ \\
\hline
\end{tabular}

Analysis 1.1. Comparison 1 DAY HOSPITAL versus OUT-PATIENT CARE - NEAR OR ON DISCHARGE, Outcome 1 Deaths (all causes) - day treatment centres.

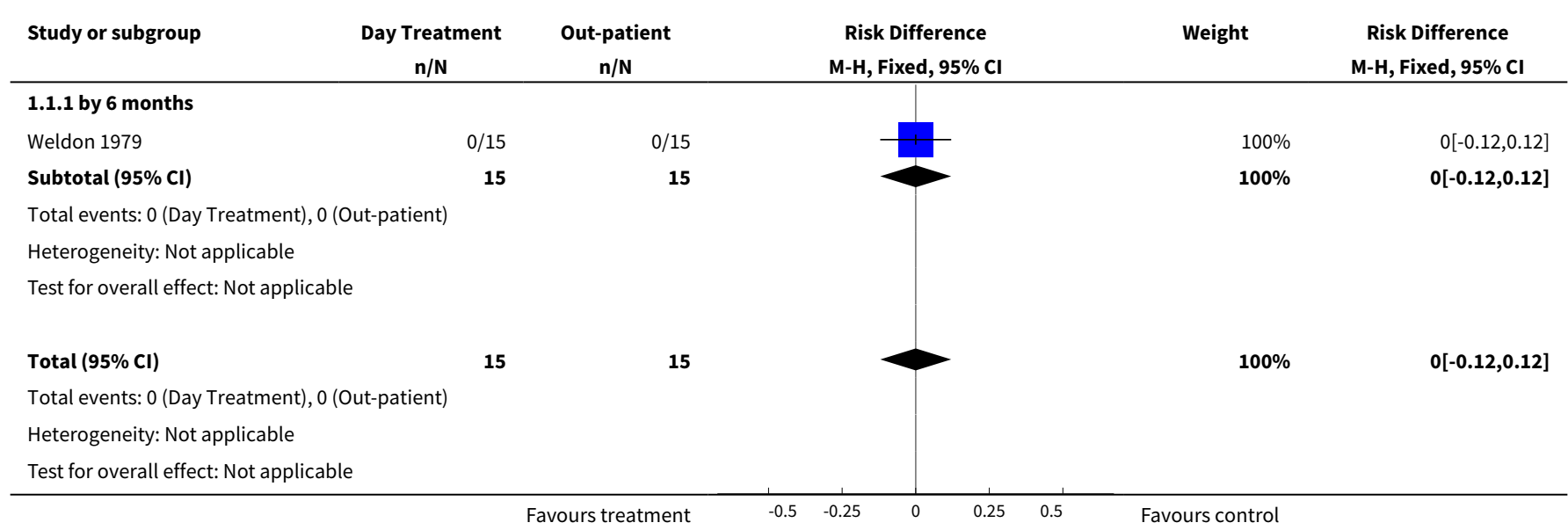


Analysis 1.2. Comparison 1 DAY HOSPITAL versus OUT-PATIENT CARE - NEAR OR ON DISCHARGE, Outcome 2 Service use: Admitted to hospital during study - day treatment centres.

\begin{tabular}{|c|c|c|c|c|c|}
\hline Study or subgroup & $\begin{array}{c}\text { Day treatment } \\
\mathrm{n} / \mathrm{N} \\
\end{array}$ & $\begin{array}{c}\text { Out-patient } \\
n / N\end{array}$ & $\begin{array}{c}\text { Risk Ratio } \\
\text { M-H, Random, } 95 \% \mathrm{CI}\end{array}$ & Weight & $\begin{array}{c}\text { Risk Ratio } \\
\text { M-H, Random, } 95 \% \mathrm{CI}\end{array}$ \\
\hline \multicolumn{6}{|l|}{ 1.2.1 by 6 months } \\
\hline Meltzoff 1966 & $7 / 40$ & $12 / 40$ & - & $100 \%$ & $0.58[0.26,1.33]$ \\
\hline Weldon 1979 & $0 / 15$ & $0 / 15$ & & & Not estimable \\
\hline Subtotal $(95 \% \mathrm{Cl})$ & 55 & 55 & & $100 \%$ & $0.58[0.26,1.33]$ \\
\hline \multicolumn{6}{|c|}{ Total events: 7 (Day treatment), 12 (Out-patient) } \\
\hline \multicolumn{6}{|c|}{ Heterogeneity: Not applicable } \\
\hline \multicolumn{6}{|c|}{ Test for overall effect: $Z=1.28(P=0.2)$} \\
\hline \multicolumn{6}{|c|}{ 1.2.2 by/at 12 months } \\
\hline Linn 1979 & $32 / 80$ & $38 / 82$ & & $68.42 \%$ & $0.86[0.61,1.23]$ \\
\hline Meltzoff 1966 & $9 / 40$ & $19 / 40$ & & $31.58 \%$ & $0.47[0.24,0.92]$ \\
\hline Subtotal $(95 \% \mathrm{CI})$ & 120 & 122 & & $100 \%$ & $0.68[0.38,1.22]$ \\
\hline \multicolumn{6}{|c|}{ Heterogeneity: $\mathrm{Tau}^{2}=0.11 ; \mathrm{Chi}^{2}=2.49, \mathrm{df}=1(\mathrm{P}=0.11) ; \mathrm{I}^{2}=59.86 \%$} \\
\hline \multicolumn{6}{|c|}{ Test for overall effect: $Z=1.29(P=0.2)$} \\
\hline \multicolumn{6}{|c|}{ 1.2.3 beyond 12 months } \\
\hline Linn 1979 & $44 / 80$ & $55 / 82$ & & $71.16 \%$ & $0.82[0.64,1.05]$ \\
\hline Meltzoff 1966 & $10 / 40$ & $23 / 40$ & 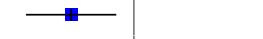 & $28.84 \%$ & $0.43[0.24,0.79]$ \\
\hline Subtotal $(95 \% \mathrm{Cl})$ & 120 & 122 & & $100 \%$ & $0.63[0.34,1.19]$ \\
\hline \multicolumn{6}{|c|}{ Total events: 54 (Day treatment), 78 (Out-patient) } \\
\hline \multicolumn{6}{|c|}{ Heterogeneity: $\mathrm{Tau}^{2}=0.16 ; \mathrm{Chi}^{2}=3.9, \mathrm{df}=1(\mathrm{P}=0.05) ; \mathrm{I}^{2}=74.38 \%$} \\
\hline Test for overall effec & & & & & \\
\hline
\end{tabular}

$\begin{array}{lllllll}\text { Favours day treatment } & 0.05 & 0.2 & 1 & 5 & 20 & \text { Favours out-patient }\end{array}$

Analysis 1.3. Comparison 1 DAY HOSPITAL versus OUT-PATIENT CARE - NEAR OR ON DISCHARGE, Outcome $3 \mathrm{Global}$ state: 1 . Number lost to follow up - day treatment centres / transitional day hospital.

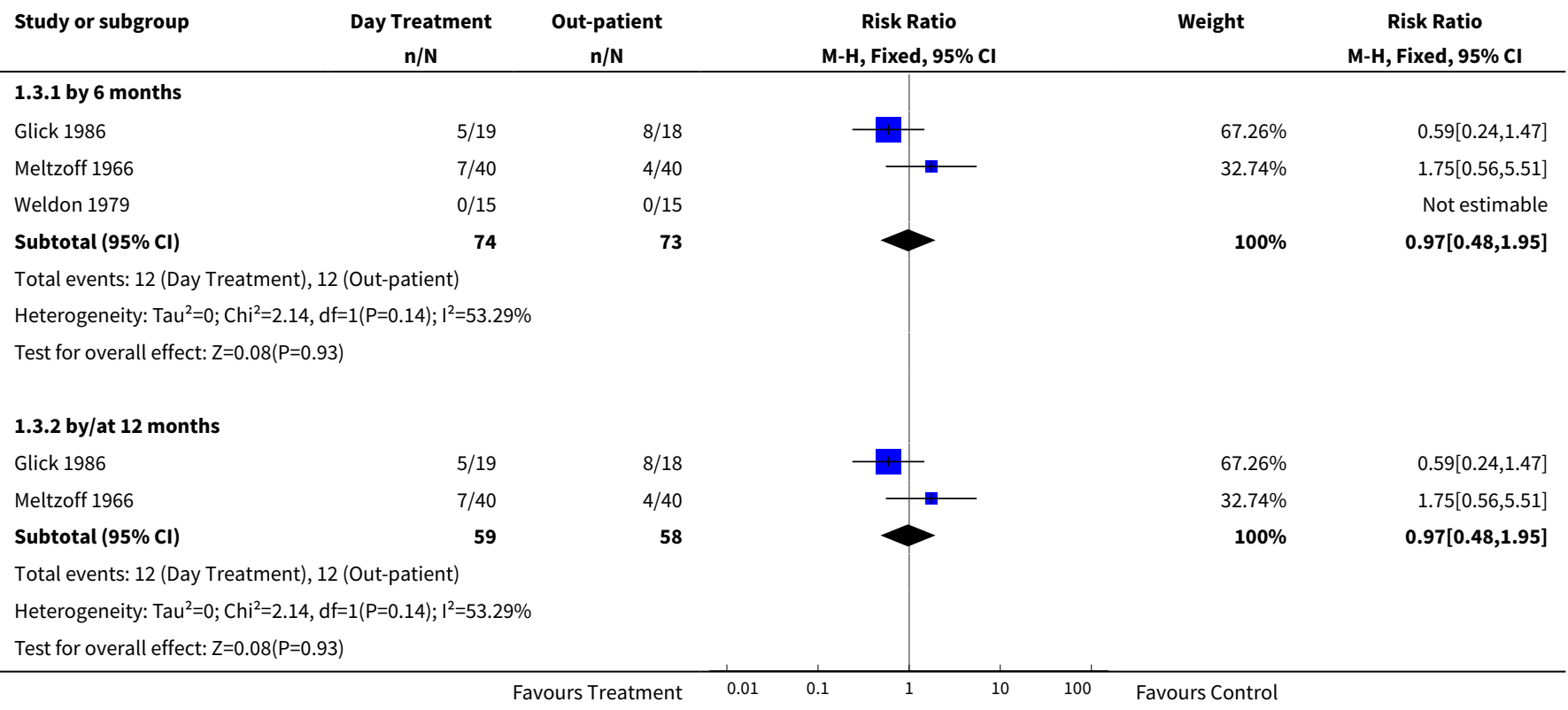




\section{Analysis 1.4. Comparison 1 DAY HOSPITAL versus OUT-PATIENT CARE - NEAR OR ON DISCHARGE, Outcome 4 Global state: 2 . Average score (GAS, high score = good) - transitional day hospital.}

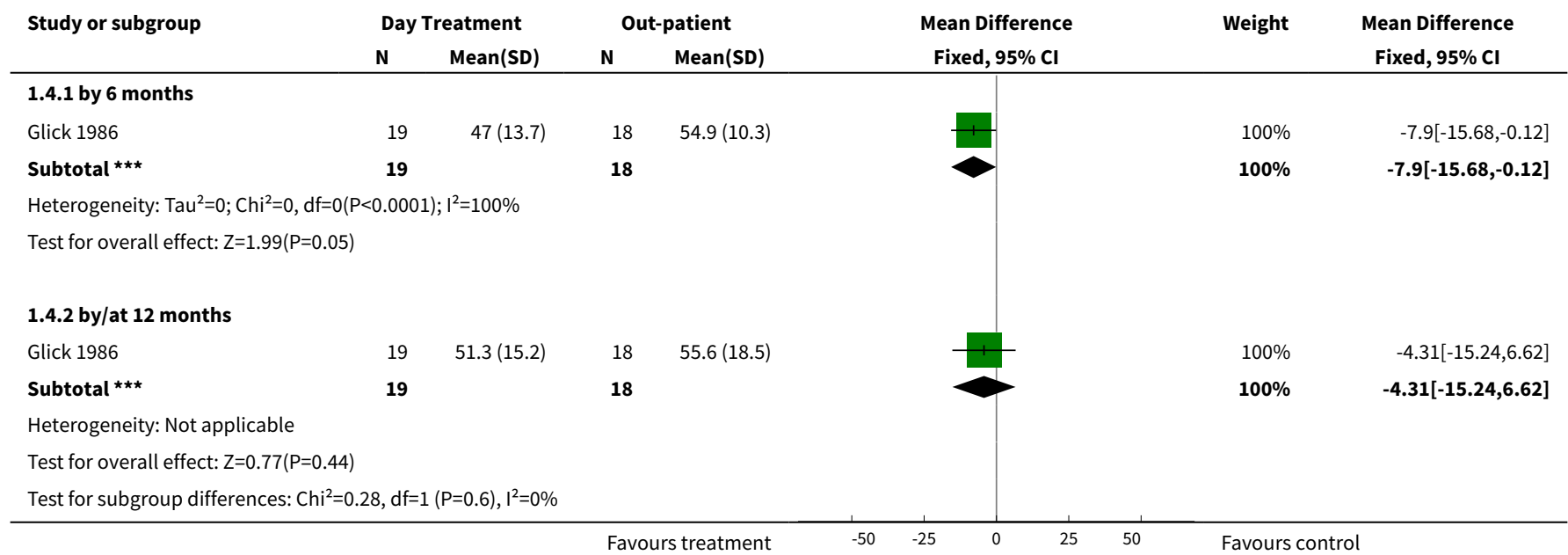

Analysis 1.5. Comparison 1 DAY HOSPITAL versus OUT-PATIENT CARE - NEAR OR ON DISCHARGE, Outcome 5 Social functioning: 1a. Average score (CAS, high score = bad) - day treatment centres.

\begin{tabular}{|c|c|c|c|c|c|c|c|}
\hline \multirow[t]{2}{*}{ Study or subgroup } & \multicolumn{2}{|c|}{ Day Treatment } & \multicolumn{2}{|c|}{ Out-patient } & \multirow{2}{*}{$\begin{array}{c}\text { Mean Difference } \\
\text { Fixed, } 95 \% \mathrm{Cl}\end{array}$} & \multirow[t]{2}{*}{ Weight } & \multirow{2}{*}{$\begin{array}{c}\text { Mean Difference } \\
\text { Fixed, } 95 \% \mathrm{Cl}\end{array}$} \\
\hline & $\mathbf{N}$ & Mean(SD) & $\mathbf{N}$ & $\operatorname{Mean}(S D)$ & & & \\
\hline \multicolumn{8}{|l|}{ 1.5.1 by 6 months } \\
\hline Weldon 1979 & 15 & $3.5(0.3)$ & 15 & $3.5(0.4)$ & & $100 \%$ & $-0.03[-0.3,0.24]$ \\
\hline Subtotal $* \star \star$ & 15 & & 15 & & & $100 \%$ & $-0.03[-0.3,0.24]$ \\
\hline \multicolumn{8}{|l|}{ Heterogeneity: Not applicable } \\
\hline Test for overall effect: $Z=0.21(P=0.83)$ & & & & & & & \\
\hline
\end{tabular}

Analysis 1.6. Comparison 1 DAY HOSPITAL versus OUT-PATIENT CARE - NEAR OR ON DISCHARGE, Outcome 6 Social functioning: 1b. Average score (SAS, high score = bad) - transitional day hospital.

\begin{tabular}{|c|c|c|c|c|c|c|c|}
\hline \multirow[t]{2}{*}{ Study or subgroup } & \multicolumn{2}{|c|}{ Treatment } & \multicolumn{2}{|c|}{ Control } & \multirow{2}{*}{$\begin{array}{c}\text { Mean Difference } \\
\text { Fixed, } 95 \% \mathrm{Cl}\end{array}$} & \multirow[t]{2}{*}{ Weight } & \multirow{2}{*}{$\begin{array}{c}\text { Mean Difference } \\
\text { Fixed, } 95 \% \mathrm{Cl}\end{array}$} \\
\hline & $\mathbf{N}$ & Mean(SD) & $\mathbf{N}$ & Mean(SD) & & & \\
\hline \multicolumn{8}{|l|}{ 1.6.1 by 6 months } \\
\hline Glick 1986 & 19 & $2.4(0.6)$ & 18 & $2(0.7)$ & & $100 \%$ & $0.36[-0.07,0.79]$ \\
\hline Subtotal $\star \star \star$ & 19 & & 18 & & & $100 \%$ & $0.36[-0.07,0.79]$ \\
\hline \multicolumn{8}{|c|}{ Heterogeneity: Not applicable } \\
\hline \multicolumn{8}{|c|}{ Test for overall effect: $Z=1.63(P=0.1)$} \\
\hline \multicolumn{8}{|c|}{ 1.6.2 by/at 12 months } \\
\hline Glick 1986 & 19 & $2.3(0.5)$ & 18 & $2.1(0.8)$ & & $100 \%$ & $0.17[-0.25,0.59]$ \\
\hline Subtotal $\star \star \star$ & 19 & & 18 & & & $100 \%$ & $0.17[-0.25,0.59]$ \\
\hline \multicolumn{8}{|c|}{ Heterogeneity: Not applicable } \\
\hline Test for overall effect & & & & & & & \\
\hline
\end{tabular}




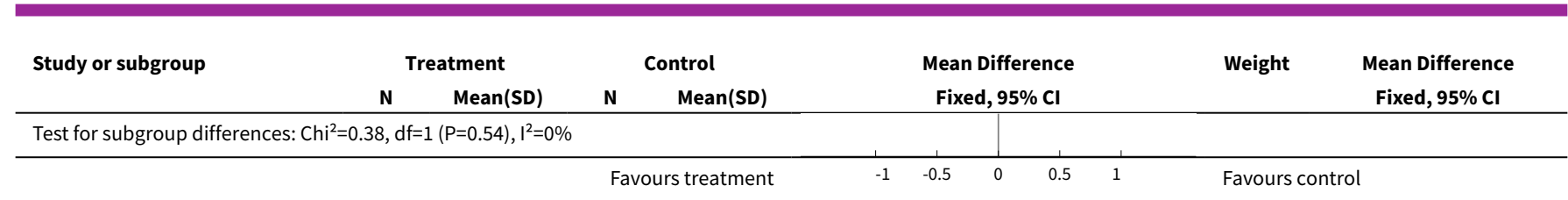

Analysis 1.7. Comparison 1 DAY HOSPITAL versus OUT-PATIENT CARE - NEAR OR ON DISCHARGE, Outcome 7 Social functioning: 2. Unemployed - day treatment centres.

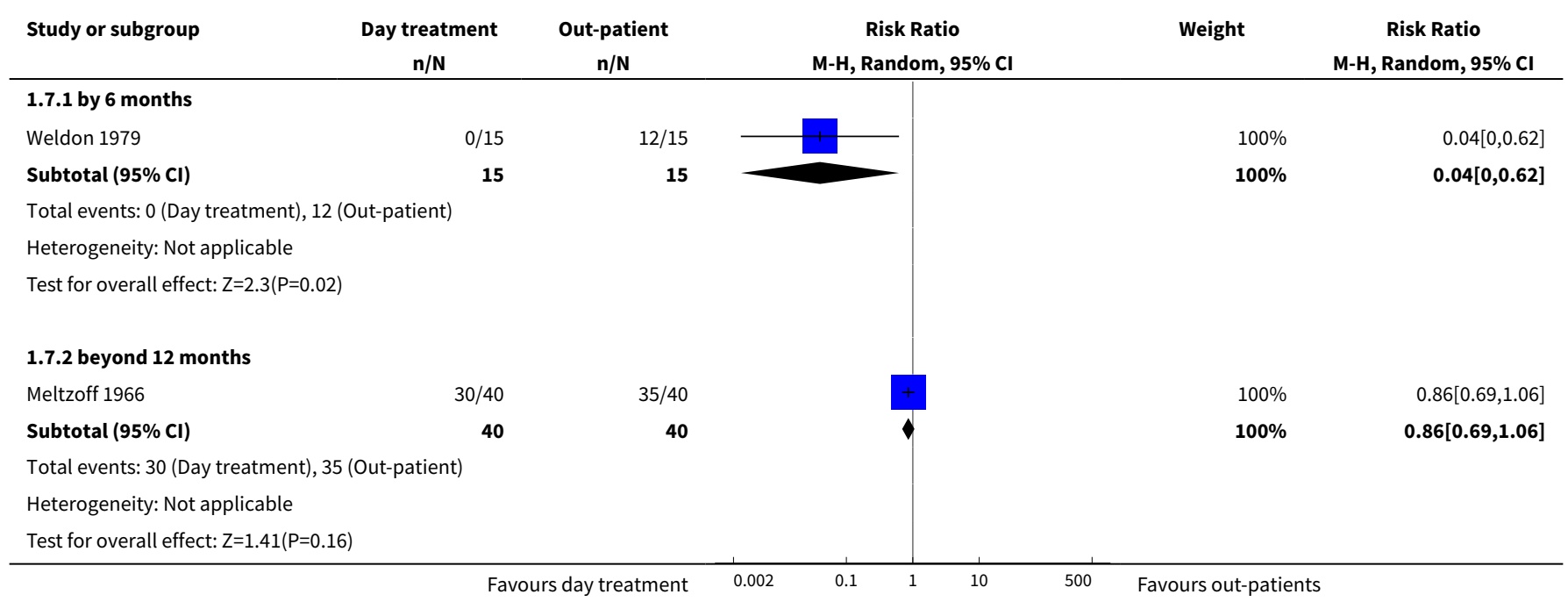

\section{Analysis 1.8. Comparison 1 DAY HOSPITAL versus OUT-PATIENT CARE - NEAR OR ON DISCHARGE, Outcome 8 Mental state: 1a. Average score $(\mathrm{PEF}$, high score = good) - transitional day hospital.}

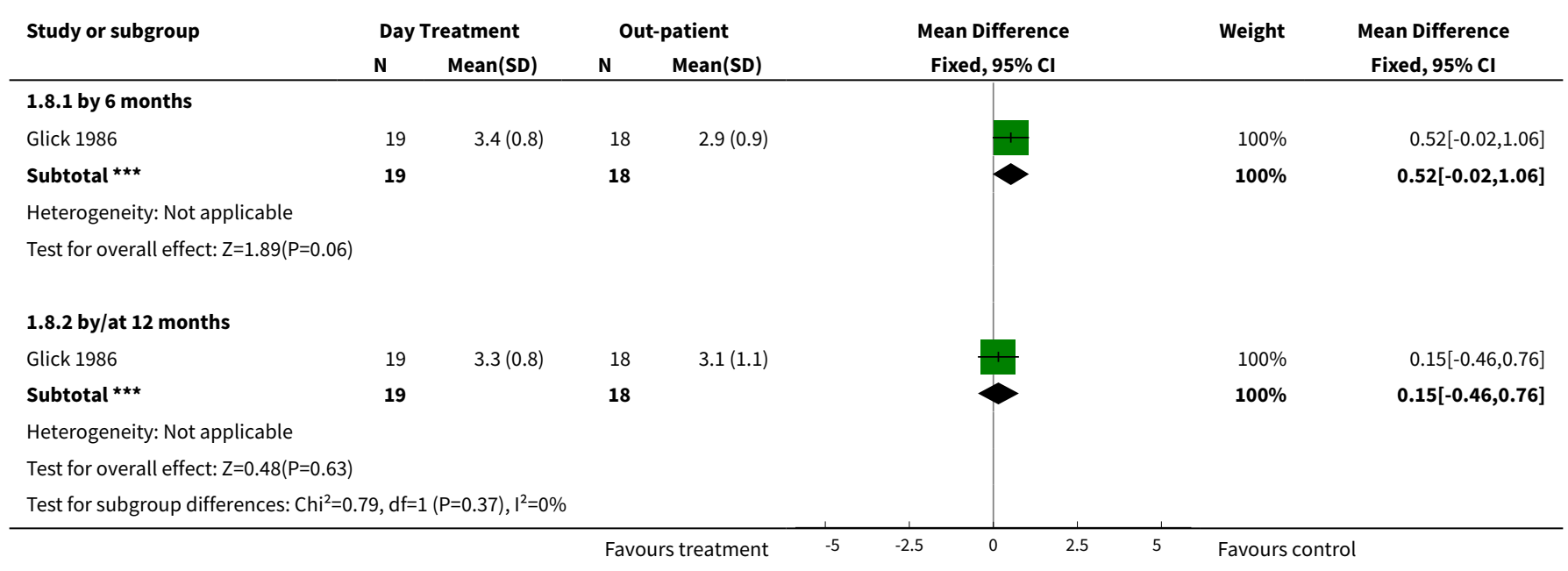


Analysis 1.9. Comparison 1 DAY HOSPITAL versus OUT-PATIENT CARE - NEAR OR ON DISCHARGE, Outcome 9 Mental state: 1 b. Average score (POMS, high score = bad) - day treatment centres.

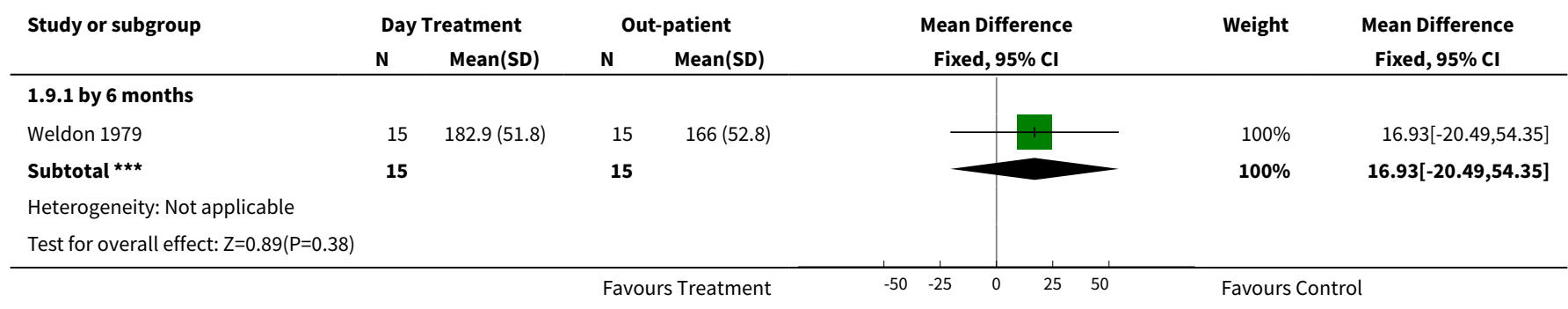

\section{Analysis 1.10. Comparison 1 DAY HOSPITAL versus OUT-PATIENT CARE - NEAR OR ON DISCHARGE, Outcome 10 Mental state: 1 c. Average score $(S C L 90$, high score = bad) - day treatment centres.}

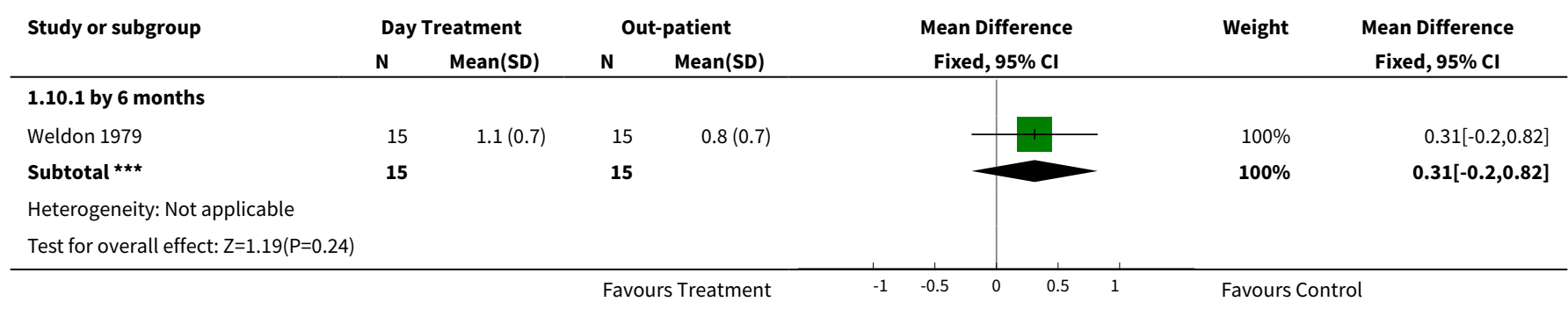

\section{ADDITIONAL TABLES}

Table 1. Suggested design for future study

\begin{tabular}{ll}
\hline Methods & Allocation: randomised, clearly described. \\
& Follow up: three years. \\
& Blindness: blinded rates, blindness tested. \\
& Analysis: intention-to-treat. \\
\hline Participants & Diagnosis: schizophrenia (clinical diagnosis). \\
& N=300. \\
Age: adults. \\
Sex: both. \\
History: recently discharged.
\end{tabular}

Interventions

1. Day hospital care - medication management, supportive \& group therapy; recreational activities, group therapy, counselling, occupational therapy, medication follow up, patient/staff ratio clearly reported.

2. Outpatient care - OP drug management no other aftercare.

$\begin{array}{ll}\text { Outcomes } & \text { Primary outcomes. } \\ & \text { 1. Service use. } \\ & 1.1 \text { Mean number of days per month in hospital. } \\ \text { Secondary outcomes. } \\ \text { 1. Death - suicide and all causes. } \\ \text { 2. Service use. }\end{array}$


Table 1. Suggested design for future study (Continued)

2.1 Hospitalisation: Admitted to hospital across time.

2.2 Hospitalisation: Number of admissions across time.

2.3 Use of services outside of mental health provision (i.e. emergency services).

3. Global state.

3.1 Leaving the study early (lost to follow up).

3.2 Relapse.

3.3 Compliance with medication.

4. Social functioning.

4.1 Imprisonment (i.e. police contacts and arrests).

4.2 Employment status (number unemployed at end of study).

5. Behaviour

5.1 Specific behaviours (i.e. self-harm; injury to others or property)

6. Quality of life.

6.1 Number of healthy days.

6.2 Satisfaction with care.

7. Economic: costs of care (taking into account cost of inpatient stay).

\section{APPENDICES}

\section{Appendix 1. Search used for previous version of this review (2001)}

\section{Electronic searches}

The search began by deriving a list of search terms from reading overviews of the field and consulting experts in day hospital care. The reference databases listed below were searched.

1. CINAHL (January 1982 - December 2000) was searched using the Cochrane Schizophrenia Group's search strategy for randomised controlled trials combined with the phrase:

[((DAY adj2 HOSP*) or (DAY adj2 CARE) or (DAY adj2 TREATMENT*) or (DAY adj2 CENT*) or (DAY adj2 UNIT*) or (PARTIAL adj2 HOSP*) or (DISPENSARY)) AND MENTAL DISORDERS].

2. The Cochrane Library (Issue 4, 2000) was searched using the phrases:

[((DAY near HOSP*) or (DAY near CARE) or (DAY near TREATMENT*) or (DAY near CENT*) or (DAY near UNIT*) or (PARTIAL near HOSP*) or (DISPENSARY)) AND MENTAL DISORDERS exploded].

3. EMBASE (January 1980 - December 2000) was searched using the Cochrane Schizophrenia Group's search strategy for randomised controlled trials combined with the phrase:

[AND ((DAY adj2 HOSP*) or (DAY adj2 CARE) or (DAY adj2 TREATMENT*) or (DAY adj2 CENT*) or (DAY adj2 UNIT*) or (PARTIAL adj2 HOSP*) or (DISPENSARY)) AND MENTAL DISORDERS].

4. MEDLINE (January 1966 - December 2000) was searched using the Cochrane Schizophrenia Group's search strategy for randomised controlled trials combined with the phrase:

[AND ((DAY adj2 HOSP*) or (DAY adj2 CARE) or (DAY adj2 TREATMENT*) or (DAY adj2 CENT*) or (DAY adj2 UNIT*) or (PARTIAL adj2 HOSP*) or (DISPENSARY)) AND MENTAL DISORDERS/All subheadings exploded].

5. PsycLIT (January 1967 - December 2000) was searched using the Cochrane Schizophrenia Group's search strategy for randomised controlled trials combined with the phrase:

[AND ((DAY adj2 HOSP*) or (DAY adj2 CARE) or (DAY adj2 TREATMENT*) or (DAY adj2 CENT*) or (DAY adj2 UNIT*) or (PARTIAL adj2 HOSP*) or (DISPENSARY)) AND MENTAL DISORDERS]. 


\section{Searching other resources}

1. Reference searching

The sensitivity of the search strategy was examined by comparing the results of the search with the reference lists of the identified reviews and trials, but no new trials were identified.

2. Personal contact

Researchers in the field were approached to identify unpublished studies

\section{Appendix 2. Methods used in previous version of this review (2001)}

\section{Methods}

\section{Criteria for considering studies for this review}

\section{Types of studies}

Eligible studies were randomised controlled trials comparing day hospital care (including day treatment programme, day care centre and transitional day care) against outpatient care.

\section{Types of participants}

For studies of day treatment programmes, participants were patients with non-psychotic disorders (all diagnoses) who would have been treated in outpatient care had day hospital care not been available. It was not necessary for participants to be "refractory to outpatient treatment", as there is no generally agreed definition of this term. However, the review recorded the entry criteria for each day treatment programme and took these into consideration in the analysis of results.

For studies of day care centres, participants were patients with severe long-term disorders (predominantly schizophrenia and other psychoses) who would have been followed up in outpatient care had day hospital care not been available.

For studies of transitional day care, participants were inpatients on acute psychiatric wards, who would have been discharged to outpatient care had 'transitional day care' not been available.

Studies were not eligible if they were restricted to, or included a majority of, patients who were aged under 18 or over 65 , or had a primary diagnosis of substance abuse or organic brain disorder.

\section{Types of interventions}

1. Day treatment programmes were defined as: "psychiatric day hospitals (see above) offering intensive input to patients with nonpsychotic disorders".

2. Day care centres were defined as "psychiatric day hospitals offering continuing care to patients with severe mental disorders".

3. Transitional day hospitals were defined as "psychiatric day hospitals offering time-limited care to patients discharged from inpatient care".

4. Standard outpatient care.

\section{Types of outcome measures}

\section{Primary outcomes}

1. Readmission to hospital

1.1 number admitted to inpatient care

\section{Secondary outcomes}

1. Engagement with treatment

1.1 number lost to follow up.

2. Readmission to hospital:

2.1 mean days in inpatient care

3. Clinical outcomes

3.1 mental state

3.2 social functioning

3.3 quality of life

3.4 death

3.5 burden on relatives

3.6 satisfaction with care

4. Cost of care

Day hospital versus outpatient care for people with schizophrenia (Review) 
4.1 mean monthly cost of psychiatric care (comprising cost of hospital care plus cost of all ambulatory psychiatric care)

4.2 mean monthly cost of all care (comprising cost of psychiatric care plus costs of other medical/social care, but excluding wages, costs to relatives, and transfer payments).

For day treatment programmes two additional outcomes were included: (1) number refusing to enter trial because unwilling to attend day hospital; and (2) self harm/self mutilation.

\section{Search methods for identification of studies}

Search methods used in the previous version of this review are reproduced in Appendix 1.

\section{Data collection and analysis}

1. Selection of trials

Abstracts of the 'hits' identified in the search were inspected independently by two reviewers (MM and AA). Potentially relevant abstracts were identified (i.e. those in which a group of day hospital patients meeting the patient inclusion criteria were compared against a control group) and full papers ordered. A reliability study found complete agreement on which trials met inclusion criteria.

\section{Assessment of quality}

Each reviewer allocated the included trials to one of three categories of allocation concealment, as described in the Cochrane Collaboration Handbook (Clarke 2000). Disagreements were resolved by discussion, or failing this, by seeking further information from the trialists. Only trials in Category A or B were included in the review (i.e. randomised trials where method of allocation concealment was either adequate or unclear). Trials were also rated on degree of blindness. Blinding of patients and treating clinicians is not possible in a trial of day hospital treatment, but trials were rated on independence and blinding of evaluators (non-independent evaluators being defined as being also involved in the treatment of trial patients).

\section{Data collection}

Data were extracted independently by three reviewers (MM, AA and RC) and cross-checked. Where further clarification was needed the authors of trials were contacted to provide missing data.

\section{Data synthesis}

4.1 Incomplete data

Data were excluded if they could not be analysed on an intention-to-treat basis, for example if there was exclusion of subjects postrandomisation for reasons other than loss to follow up. Data were also excluded from studies where more than $50 \%$ of subjects were lost to follow up (except for the outcome of 'lost to follow up').

\subsection{Binary data}

For binary outcomes a standard estimation of the risk ratio (RR) and its $95 \%$ confidence interval $(\mathrm{Cl})$ was calculated. If the relative risk was significant, the number needed to treat statistic (NNT) was also calculated. If heterogeneity was found (see section 5) a random-effects model was used.

\subsection{Continuous data}

4.3.1 Summary statistic: for continuous outcomes a weighted mean difference (WMD) between groups was estimated. Continuous data presented without use of summary statistics (i.e. mean, SD/SE or non-parametric equivalent) were not considered good evidence, though the existence of such data was noted in the text.

4.3.2 Valid scales: unpublished scales are known to be subject to bias in trials of treatments for schizophrenia (Marshall 2000). Therefore continuous data from rating scales were included only if the measuring instrument had been described in a peer-reviewed journal and the instrument was either a self report or completed by an independent evaluator or relative (not the therapist).

4.3.3 Individual patient data: individual patient data were not sought for this review, however one author (PT) provided individual patient data. These data were verified against the original trial reports, and permitted a rating of social functioning to be upgraded from a mention in the text to an entry on RevMan (as summary statistics were then available). Exclusion of these data do not alter the main conclusions of the review.

5. Test for heterogeneity

A Chi-square test was used, as well as visual inspection of graphs, to investigate the possibility of heterogeneity. A significance level less than 0.10 was interpreted as evidence of heterogeneity. If heterogeneity was found the data were re-analysed using a random-effects model. If this made a substantial difference, the studies responsible for the heterogeneity were presented separately from the main body of homogeneous trials and the reasons for heterogeneity were investigated.

\section{Addressing publication bias}

There were insufficient data to address the question of publication bias. Had sufficient data been available, they would have been entered into a funnel graph (trial effect against trial size) in an attempt to investigate the likelihood of overt publication bias (Egger 1997). 
7. Sensitivity analyses

Sensitivity analyses were not performed for lack of adequate data (see results below). With more data, sensitivity analyses would have been used to examine the effect of excluding studies with (a) high attrition rates ( $>75 \%$ ); (b) non-independent or non-blind raters; and (c) allocation concealment in category B.

8. General

Where possible, reviewers entered data so that the area to the left of the line of no effect indicated a favourable outcome for the intervention (i.e. day treatment programme or day care centre).

\section{WHAT'S NEW}

\begin{tabular}{lll}
\hline Date & Event & Description \\
\hline 6 October 2010 & Amended & Contact details updated. \\
\hline
\end{tabular}

\section{H I S T O R Y}

Protocol first published: Issue 4, 1997

Review first published: Issue 3, 2001

\begin{tabular}{lll}
\hline Date & Event & Description \\
\hline 14 April 2010 & Amended & Contact details updated. \\
\hline 15 February 2010 & Amended & Contact details updated. \\
\hline 12 August 2009 & $\begin{array}{l}\text { New citation required but conclusions } \\
\text { have not changed }\end{array}$ & Completely restructured, entry criteria is changed. \\
\hline 12 August 2009 & New search has been performed & $\begin{array}{l}\text { Completely restructured, entry criteria is changed, title changed } \\
\text { to focus on people with schizophrenia. }\end{array}$ \\
\hline 23 October 2008 & Amended & Converted to new review format. \\
\hline
\end{tabular}

\section{CONTRIBUTIONSOF AUTHORS}

Elena Shek - updated the review in 2009 - updated methods, co-ordinated the review, undertook searches, screened search results, appraised papers, extracted data, entered them into RevMan, analysed data, interpreted the findings and took a lead in writing the final report of 2009.

Airton Stein - updated review in 2009 - updated methods, screened search results, cross-checked data extraction, helped interpret findings and write the report.

Flavio Shansis - updated review in 2009 - updated methods, screened search results, cross-checked data extraction, helped interpret findings and write the report.

Max Marshall - led first version of the review, designed original methods, co-ordinated the review, collected data, undertook search strategy, screened search results, appraised papers, extracted data, compiled individual patient data, cross-checked these data against trial reports, analysed data, interpreted the data and wrote the report of 2001. In the 2009 update helped advise on methods and write final report.

Ruth Crowther - worked solely on first version of review - helped co-ordinate review, collect data, cross-check data extraction, manage data, entered them into RevMan, compiled individual patient data, cross-checked them against trial reports, analysed data, interpreted them and helped write the original report

Peter Tyrer - worked mainly on first version of review - prepared and provided individual patient data, helped analyse data, interpret results and write final report. 


\section{DECLARATIONS OF INTEREST}

None known. Peter Tyrer has undertaken a trial of day hospital treatment but this was for participants not relevant to the 2009 update of this review and therefore has been excluded.

\section{SOURCES OF SUPPORT}

\section{Internal sources}

- Institute of Clinical Research India, Bangalore, India.

- School of Health, Cranfield University, UK.

- Universidade Federal de Ciências da Saúde, Porto Alegre, Brazil.

- Ulbra and Grupo Hospitalar Conceição, Porto Alegre, Brazil.

- Sao Pedro Hospital, Porto Alegre, Brazil.

\section{External sources}

- No sources of support supplied

\section{DIFFERENCES BETWEEN PROTOCOLANDREVIEW}

This is an update of an old review and with that comes a major revision of the methods from the earlier version. The 'methods' section of the first version of this review is appended (Appendix 2).

\section{INDEX TERMS}

\section{Medical Subject Headings (MeSH)}

Aftercare; Ambulatory Care [standards]; Day Care, Medical [economics] [standards]; Hospitals, Psychiatric; Mental Disorders [therapy]; Program Evaluation; Randomized Controlled Trials as Topic; Schizophrenia [^therapy]

\section{MeSH check words}

Humans 